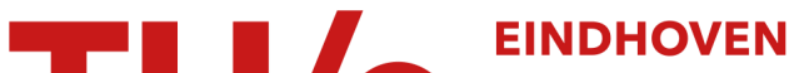 \\ UNIVERSITY OF \\ TECHNOLOGY
}

\section{SCC modification by use of amorphous nano-silica}

Citation for published version (APA):

Quercia Bianchi, G., Spiesz, P. R., Hüsken, G., \& Brouwers, H. J. H. (2014). SCC modification by use of amorphous nano-silica. Cement \& Concrete Composites, 45, 69-81.

https://doi.org/10.1016/j.cemconcomp.2013.09.001

DOI:

10.1016/j.cemconcomp.2013.09.001

Document status and date:

Published: 01/01/2014

\section{Document Version:}

Publisher's PDF, also known as Version of Record (includes final page, issue and volume numbers)

\section{Please check the document version of this publication:}

- A submitted manuscript is the version of the article upon submission and before peer-review. There can be important differences between the submitted version and the official published version of record. People interested in the research are advised to contact the author for the final version of the publication, or visit the $\mathrm{DOI}$ to the publisher's website.

- The final author version and the galley proof are versions of the publication after peer review.

- The final published version features the final layout of the paper including the volume, issue and page numbers.

Link to publication

\section{General rights}

Copyright and moral rights for the publications made accessible in the public portal are retained by the authors and/or other copyright owners and it is a condition of accessing publications that users recognise and abide by the legal requirements associated with these rights.

- Users may download and print one copy of any publication from the public portal for the purpose of private study or research.

- You may not further distribute the material or use it for any profit-making activity or commercial gain

- You may freely distribute the URL identifying the publication in the public portal.

If the publication is distributed under the terms of Article 25fa of the Dutch Copyright Act, indicated by the "Taverne" license above, please follow below link for the End User Agreement:

www.tue.nl/taverne

Take down policy

If you believe that this document breaches copyright please contact us at:

openaccess@tue.nl

providing details and we will investigate your claim. 


\title{
SCC modification by use of amorphous nano-silica
}

\author{
G. Quercia ${ }^{\mathrm{a}, \mathrm{b}, *}$, P. Spiesz ${ }^{\mathrm{b}}$, G. Hüsken ${ }^{\mathrm{c}}$, H.J.H. Brouwers ${ }^{\mathrm{b}}$ \\ ${ }^{a}$ Materials innovation institute (M2i), Delft, The Netherlands \\ ${ }^{\mathrm{b}}$ Eindhoven University of Technology, Eindhoven, The Netherlands \\ ${ }^{\mathrm{c}}$ BAM Federal Institute for Materials Research and Testing, Berlin, Germany
}

\section{A R T I C L E I N F O}

\section{Article history:}

Received 29 June 2012

Received in revised form 22 July 2013

Accepted 3 September 2013

Available online 8 September 2013

\section{Keywords:}

Nano-silica

Self compacting concrete

Durability

Chloride

Freeze-thaw

\begin{abstract}
A B S T R A C T
In this study two different types of nano-silica (nS) were applied in self-compacting concrete (SCC), both having similar particle size distributions (PSD), but produced through two different processes: fumed powder silica and precipitated silica in colloidal suspension. The influence of nano-silica on SCC was investigated with respect to the properties of concrete in fresh (workability) and hardened state (mechanical properties and durability). Additionally, the densification of the microstructure of the hardened concrete was verified by SEM and EDS analyses. The obtained results demonstrate that nano-silica efficiently used in SCC can improve its mechanical properties and durability. Considering the reactivity of the two applied nano-silicas, the colloidal type showed a higher reactivity at early age, which influenced the final SCC properties.
\end{abstract}

(c) 2013 Elsevier Ltd. All rights reserved.

\section{Introduction}

Nowadays, the micro-level does not provide enough insights into building materials. Therefore, all around the world, increasing amounts of funding are being directed to research projects dealing with material properties on the nano-level, which is claimed to have a tremendous potential for the future [1]. The fundamental processes that govern the properties of concrete are affected by the performance of the material on nano-scale. The main hydration product of cement-based materials, the $\mathrm{C}-\mathrm{S}-\mathrm{H}$ gel, is a nano-structured material [1-4]. The mechanical properties and the durability of concrete mainly depend on the refinement of the microstructure of the hardened cement paste and the improvement of the pasteaggregate interface zone (ITZ) [5].

One of the most referred to and used cementitious nano-materials is amorphous silica with a particle size in the nano-range, even though its application and effects on concrete have not been fully understood yet. It has been reported that the nano-silica addition enhances the compressive strength and reduces the overall permeability of hardened concrete due to its pozzolanic properties, which result in finer hydrated phases $(\mathrm{C}-\mathrm{S}-\mathrm{H}$ gel $)$ and densified microstructure (nano-filler and anti- $\mathrm{Ca}(\mathrm{OH})_{2}$-leaching effect) [6-20]. These effects may enhance the durability of concrete elements and structures.

* Corresponding author at: Materials innovation institute (M2i), Delft, The Netherlands.

E-mail address: g.quercia@tue.nl (G. Quercia).
There are different commercial types of nano-silica additives available on the market, which are produced in different ways such as precipitation, pyrolysis, sol-gel and others [19]. The main characteristics of nano-silica, such as the particle size distribution, specific density, specific surface area, pore structure and reactivity (surface silanol groups) depend on the production method [6-20]. Despite the presence of several studies describing the main properties and characteristics of concrete containing nano-silica particles, most of them focus on the application of nano-silica as an antibleeding [20-28] and compressive strength enhancing additive $[12,13,27-31]$. Furthermore, the durability and sustainability of concrete is becoming of vital importance for the construction industry. In this context, SCC is a type of concrete that has generated tremendous interest since its initial development in Japan by Okamura [21].

SCC was developed to obtain durable concrete structures due to an increased homogeneity. For this purpose, a concrete with low yield stress, moderate viscosity and high resistance to segregation, which also can be cast on-site or into precast molds without compaction, was developed. The special flow behavior of SCC is obtained by the use of superplasticizers, high amounts of fine particles, and, in some cases, viscosity modifying agents (added to reduce segregation and bleeding). Due to the presence of high amounts of fines, the pore structure of SCC differs from the pore structure of traditional concrete. According to Audenaert et al. [22], the application of SCC might be somewhat risky due to the lack of knowledge concerning the actual durability of this material.

So far, only a few reports on the effects of nano-silica on the durability of SCC are available $[27,29,31]$. In addition, the 
difference in the reactivity of nano-silica due to its production route has not been reported yet.

In this study, two different types of nano-silica were applied in SCC, both having similar particle size distributions (PSD), but produced through two different processes: fumed powder silica and precipitated silica in colloidal suspension. The influence of the nano-silica on SCC was investigated with respect to the properties of the concrete in fresh (workability) and hardened state (mechanical properties and durability indicators). Additionally, the densification of the microstructure of the hardened concrete was analyzed by SEM and EDS techniques.

\section{Materials and methods}

\subsection{Materials and SCC mix design}

The Portland cement used was CEM I 42.5N (ENCI, The Netherlands), as classified by [32]. This cement consists of at least $95 \%$ Portland cement clinker; the initial setting time is $60 \mathrm{~min}$, a water demand of $38.9 \%$ by weight, and a compressive strength of $21 \pm 3 \mathrm{~N} / \mathrm{mm}^{2}$ after 2 days and $51 \pm 4 \mathrm{~N} / \mathrm{mm}^{2}$ after 28 days, respectively, are obtained [32]. The coarse aggregates used were composed of broken granite in the fractions $2-8 \mathrm{~mm}$ and $8-16 \mathrm{~mm}$. Two different sands were used: dredged river sand $(0-4 \mathrm{~mm})$ and microsand $(0-1 \mathrm{~mm})$. The microsand (Granite Import B.V., the Netherlands) is mainly composed of natural sandstone waste that is generated during the crushing process of coarser fractions. A ground limestone powder was applied as filler. Two different commercial nano-silica additives were selected to produce two different SCC batches: one colloidal nano-silica suspension and one fumed powder nano-silica. Both nano-silica additives have similar PSD and specific surface area measured by BET (Brunauer-EmmetTeller method [33]), following the standard DIN-ISO 9277-2005 [34]. Furthermore, a superplasticizer (SP) based on polycarboxylate ethers was added to adjust the workability of the mix. A summary of the general characteristics of all materials used in this study is presented in Table 1 and their PSDs are depicted in Fig. 1.

For the composition of SCC mixes, the mix design concept described in [35] was used. This design concept makes use of an optimization algorithm described in [36] to compute the mix proportions of all solid ingredients of the concrete mix, following the theory of continuously graded granular mixtures. In the optimization process, a distribution modulus $(q)$ of 0.25 was used together with the following constrains: cement content of $340 \mathrm{~kg} / \mathrm{m}^{3}, \mathrm{w} / \mathrm{c}$ ratio of 0.45 and air content in the fresh mix of $1 \%$ by volume. The cement content and the $w / c$ ratio were selected based on NEN-EN 206-1 (2008) [37] for the exposure class XS3 (aggressive exposure to chlorides originating from seawater). In addition, a flow class of the fresh concrete F7 $(630-800 \mathrm{~mm})$ was selected as a target, taking into consideration the Dutch recommendation

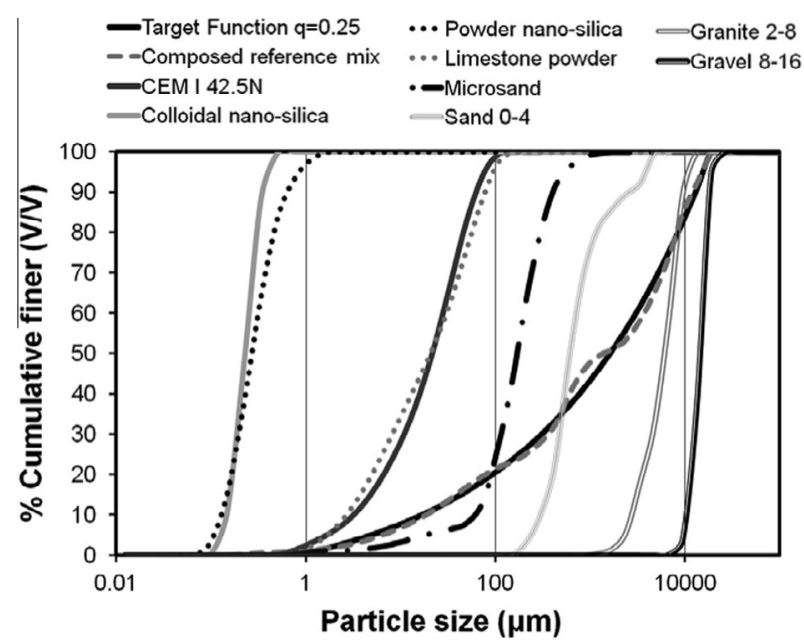

Fig. 1. PSD of the used materials, target function based on [36] and composition of reference mix (dashed line) for $D_{\min }=60 \mathrm{~nm}$.

BRL 1801 [38] for SCC. An example of the target curve and the composed grading curve of the SCC mix is shown in Fig. 1. In Table 2 the final mix proportioning and characteristics of the reference mix without nano-silica and two mixes with nano-silica addition are presented.

\subsection{Test methods}

\subsubsection{Fresh concrete properties}

Using the provided materials, three SCC mixes ( 2 batches of $65 \mathrm{dm}^{3}$ for each mix) were prepared according to the mix proportions listed in Table 2. These SCCs were mixed for $5 \mathrm{~min}$ in total in a compulsory mixer, and subsequently tested for their fresh properties, according to the procedure recommended by the EFNARC committee [39]. The following fresh-concrete properties of the SCC were determined: V-funnel time, slump flow, density, packing density and air content.

\subsubsection{Hardened concrete: mechanical properties}

To test the properties of the hardened concrete, thirty-eight cubes ( $150 \mathrm{~mm}$ side length) were cast for each mix, cured sealed during the first day, stripped from the mold after $24 \mathrm{~h}$ and cured subsequently in water until their test age was reached, according to the prescribed storing conditions given by BS-EN 12390-2 [40]. The compressive strength was determined after 1, 3, 7, 28 and 91 days on three cubes for each mix. The compressive strength test was performed according to BS-EN 12390-3 [41]. In addition, the splitting tensile strength was determined after 28 days on three cubes, following the procedure given in BS-EN 12390-6 [42].

Table 1

Properties of the used materials.

\begin{tabular}{|c|c|c|c|c|c|c|}
\hline Materials & Specific density $\left(\mathrm{g} / \mathrm{cm}^{3}\right)$ & BET $\left(\mathrm{m}^{2} / \mathrm{g}\right)$ & $\mathrm{pH}$ & Solid content $(\% \mathrm{w} / \mathrm{w})$ & Loss on ignition (LOI) & Computed SSA ${ }^{\mathrm{b}}\left(\mathrm{m}^{2} / \mathrm{m}^{3}\right)$ \\
\hline CEM I $42.5 \mathrm{~N}$ & 3.14 & 1 & - & - & 2.8 & $1,699,093$ \\
\hline Colloidal nano-silica & 1.40 & 50 & 9.5 & 50 & - & $46,110,081$ \\
\hline Powder nano-silica & 2.15 & 56 & $5.0^{\mathrm{a}}$ & - & 0.5 & $48,175,461$ \\
\hline Limestone powder & 2.71 & - & - & - & - & $1,234,362$ \\
\hline Microsand (sandstone) & 2.64 & - & - & - & - & 193,514 \\
\hline Sand $0-4$ & 2.64 & - & - & - & - & 14,251 \\
\hline Granite $2-8$ & 2.65 & - & & - & - & 1740 \\
\hline Granite 8-16 & 2.65 & - & - & - & - & 515 \\
\hline Superplasticizer & 1.10 & - & 7.0 & 35 & - & - \\
\hline
\end{tabular}

\footnotetext{
a $4 \% \mathrm{w} / \mathrm{w}$ in water.
}

b SSA is the specific surface area assuming spherical shape for nano-silica and the angularity factor of every other used granular material, following [35]. 
Table 2

Composition and characteristics of the three designed SCC mixes.

\begin{tabular}{llll}
\hline Materials & $\begin{array}{l}\text { Reference } \\
\left(\mathrm{kg} / \mathrm{m}^{3}\right)\end{array}$ & $\begin{array}{l}\text { Colloidal } \mathrm{nS} \\
\left(\mathrm{kg} / \mathrm{m}^{3}\right)\end{array}$ & $\begin{array}{l}\text { Powder } \mathrm{nS} \\
\left(\mathrm{kg} / \mathrm{m}^{3}\right)\end{array}$ \\
\hline CEM I 42.5N & 340.0 & 340.0 & 340.1 \\
Nano-silica & 0.0 & 12.8 & 12.8 \\
Limestone powder & 179.4 & 151.8 & 151.9 \\
Microsand (sandstone) & 125.0 & 141.3 & 141.4 \\
Sand 0-4 & 624.3 & 617.9 & 618.0 \\
Granite 2-8 & 733.8 & 735.6 & 735.7 \\
Granite $8-16$ & 274.7 & 274.2 & 274.3 \\
Water & 153.0 & 153.0 & 153.0 \\
SP & 3.4 & 6.5 & 6.5 \\
\hline Air $(\% \mathrm{~V})-\mathrm{estimated}$ & 1.0 & 1.0 & 1.0 \\
Density $\left(\mathrm{g} / \mathrm{cm}^{3}\right)$ & 2.427 & 2.427 & 2.430 \\
$w / c$ & 0.45 & 0.45 & 0.45 \\
$w / p$ & 0.267 & 0.270 & 0.270 \\
Powder content $\left(\mathrm{dm}^{3} / \mathrm{m}^{3}\right)$ & 194.2 & 192.7 & 192.6 \\
Composed surface $\left(\mathrm{m}^{2} / \mathrm{m}^{3}\right)$ & 277,972 & 547,905 & 554,428 \\
SP content $\left(\mathrm{g} / \mathrm{m}^{2}\right)$ & 0.0122 & 0.0119 & 0.0117 \\
SP content $\left(\% \mathrm{bwoc}^{3}\right.$ & 1.0 & 1.9 & 1.9 \\
\hline
\end{tabular}

bwoc: based on the weight of cement.

\subsubsection{Hardened concrete: durability tests}

2.2.3.1. Permeable (water accessible) porosity. The permeable porosity affects the transport properties of fluids in concrete and therefore also its durability. It is related to many deterioration processes driven by the transport properties of concrete [43]. In this context, three cores (diameter of $100 \mathrm{~mm}$, height of $150 \mathrm{~mm}$ ) were drilled with a diamond coring bit from three cubes for each mix. Afterwards, using a diamond saw at medium speed lubricated with water, six concrete discs (height of approximately $15 \mathrm{~mm}$ ) for each SCC mix were cut from the inner layers of the drilled cores. No polishing of the surfaces was performed. In total 18 discs were used to determine the permeable porosity, following the procedure described in the ASTM 1202 [44]. The vacuum-saturation technique was applied to fill the accessible pores with water, as this technique is concluded to be the most efficient by Safiuddin and Heran [43].

2.2.3.2. Penetration of water under pressure. The depth of penetration of water under pressure was tested according to BS-EN $12390-8$ [45] at the age of 28 days. The samples (three cubes for the reference and two for each mix with nano-silica) were exposed to water under pressure ( 5 bar) for $72 \mathrm{~h}$ and subsequently split in order to determine the maximum depth of the water penetration.

2.2.3.3. Pore size distribution and porosity of the paste. The pore size distribution was measured using the mercury intrusion porosimetry (MIP) technique (Autopore IV, Micromeretics). The maximum applied pressure of mercury was $228 \mathrm{MPa}$, the mercury contact angle was $130^{\circ}$ and the equilibrium time was $20 \mathrm{~s}$. The pore size range of $0.0063-900 \mu \mathrm{m}$ was investigated. Pieces of hardened mortar (approximately 2 grams in total) were carefully selected to avoid the presence of coarse sand and gravel. The mortars, extracted from cured SCC samples at 28 days, were first dried in an oven $\left(80^{\circ} \mathrm{C}\right)$ until a constant mass was reached, and then tested by MIP technique.

2.2.3.4. Rapid chloride migration test (RCM) and conductivity test. Two specimens for the RCM test were retrieved from each extracted core, as described in Section 2.2.3.1, giving in total six test specimens (discs, diameter of $100 \mathrm{~mm}$ and height of $50 \mathrm{~mm}$ ) for each mix. Three of these specimens were tested at the age of 28 days and the remaining three at 91 days. One day prior to the RCM test, the specimens were pre-conditioned (vacuum-saturation with limewater). The RCM test was performed according to NT
Build 492 [46], using the test set-up described in [47]. The duration of the RCM test for all samples was $24 \mathrm{~h}$. After the test, the penetration depth of chlorides was measured on split samples by applying a colourimetric indicator for chlorides $\left(0.1 \mathrm{M} \mathrm{AgNO}_{3}\right.$ solution) and the values of the chloride migration coefficients $\left(D_{\mathrm{RCM}}\right)$ were calculated according to [46].

Before the RCM test, the electrical resistance was measured on the same saturated samples by using the so-called 'two electrodes' method [48]. For this, an AC test signal ( $f=1 \mathrm{kHz}$ ) was applied between two stainless-steel electrodes and the resistance of the concrete sample placed between the electrodes was registered. Finally, the conductivity of the samples was calculated taking into account their thicknesses and transversal areas.

2.2.3.5. Chloride diffusion test. As the addition of nano-silica changes the ionic strength, the $\mathrm{pH}$ and the conductivity of the pore solution [49], the results obtained using the RCM test may be influenced, as the procedure of this test is based only on experience with OPC systems [50]. At the same time, the natural chloride diffusion test is only affected by the pore structure (permeability and tortuosity of the pores), chloride binding and chloride concentration gradient. Thus, the chloride diffusion test may be more reliable for SCC with nano-silica addition than the RCM test.

For each prepared mix, three specimens (cylinders, diameter of $100 \mathrm{~mm}$ and height of $50 \mathrm{~mm}$ ) were extracted from different cubes by drilling and then cutting. The diffusion test began 28 days after casting the concrete, following the procedure described in [51]. Prior to the test, all external faces of the specimens were coated with an epoxy resin except for one flat surface, left uncovered to allow the chlorides to penetrate the samples just from that side. Then, the specimens were immersed in a sodium chloride solution (concentration of $165 \mathrm{~g} / \mathrm{dm}^{3}$ ) for 63 days at room temperature in a sealed and de-aired container with the uncoated surface on top. After the exposure period, one specimen from each test series was split in order to measure the penetration depth of chlorides (using $0.1 \mathrm{M} \mathrm{AgNO}_{3}$ solution as a colourimetric chloride indicator). The remaining samples were dry-ground in layers for determining chloride concentration profiles. The grinding was performed on an area of $73 \mathrm{~mm}$ in diameter using the Profile Grinder 1100 (Germann Instruments). The obtained powder was collected for determining chloride profiles, following the procedure described in [52]. An automatic potentiometric titration unit was used for the $\mathrm{Cl}^{-}$ concentration measurements, applying a $0.01 \mathrm{M} \mathrm{AgNO}_{3}$ solution as titrant. The obtained chloride concentration values were fit to the solution of Fick's 2nd law, in order to estimate the apparent chloride diffusion coefficient $\left(D_{\text {app }}\right)$ and the surface chloride concentration.

2.2.3.6. Freeze-thaw resistance (surface scaling test). As a further durability assessment, the freeze-thaw test was performed on SCC samples, even though the air content in the fresh mix was less than the recommended value of $4 \%$ by volume [37]. The freezethaw resistance, expressed by the surface scaling factor (Sn), was determined following NEN-EN 12390-9 [53]. Nevertheless, the test samples differed from the specifications in the standard. For practical reasons, cylinders were used instead of slabs. The $150 \mathrm{~mm}$ cubes were cured in water after demolding until the age of 14 days, when the cores (100 $\mathrm{mm}$ in diameter) were extracted and sliced (two cylinders of $50 \mathrm{~mm}$ in height were obtained from each core). Afterwards, the obtained cylinders were cured under water and then sealed after 25 days with tight rubber sleeves. The sealed samples were placed in polyurethane insulations of $10 \mathrm{~mm}$ thickness and surface-saturated with demineralized water for 3 days. Due to a limited volume of the used climate chamber, only three specimens were tested for each mix, resulting in a total exposed surface area of $0.024 \mathrm{~m}^{2}$ (the area recommended in [53] is 
$0.08 \mathrm{~m}^{2}$ ). After the saturation, the demineralized water was replaced by a $3 \mathrm{~mm}$ layer of $3 \%$ by weight $\mathrm{NaCl}$ solution, poured on the top surfaces of the samples and then the freeze-thaw cycles were started. The applied temperature profile was following the recommendations given in NEN-EN 12390-9 [53]. The level of solution on the surface of concrete was adjusted regularly. In total, 56 freeze-thaw cycles were performed, during which the surface scaling was measured after 7, 14, 28, 42 and 56 cycles.

\subsubsection{Microstructural characterization and analysis}

The microstructural morphology of the prepared concrete was analyzed using a high resolution scanning electron microscope (FEI Quanta 600 FEG-SEM) with a Schottky field emitter gun (at voltage of $10 \mathrm{keV}$ and $0.6 \mathrm{mbar}$ of low-vacuum pressure). Furthermore, a general chemical analysis was performed using EDAX energy dispersive spectroscopy (EDS) detector. Several fracture surfaces were investigated in natural conditions (without any sample preparation). The fracture surfaces of the SCC samples were analyzed in this study to avoid the effect of sample preparation (cutting, grinding, polishing, etc.), which may alter the microstructure of concrete. In the analyses of the fracture surfaces it is possible to characterize the interfacial transition zone (ITZ) and the formation of ettringite.

\section{Results and discussion}

\subsection{Fresh concrete properties}

The fresh concrete properties of the tested mixes are presented in Table 3. All three mixes fulfill the requirements for the flow class F7 (630-800 mm of spread diameter), specified in BRL 1801 [38]. Only the mix with colloidal nano-silica resulted in a spread flow close to the lower limit of this target range. Another interesting finding is that the SP content, based on the composed surface area, is nearly constant for all mixes and amounts to an average value of $0.0119 \mathrm{~g} / \mathrm{m}^{2}$. This shows that in the present case the required amount of SP can be calculated if the composed surface area of all solid ingredients is known. Nevertheless, the SP dosage depends mainly on the mineralogy and the surface charge of the fine particles [54,55]. Another implication of this result is that the SP requirement is rather related to changes in the specific surface area of the mix than to the concentration (by mass) of the nano-silica addition, as it was previously reported by Sobolev et al. [17]. These researchers concluded that $0.21 \%$ of additional SP is needed for each $1 \%$ of nano-silica added to a standard concrete composition.

Considering the V-funnel time, only the two mixes with nanosilica fulfill the requirements of the viscosity class VF2 (funnel time 9-25 s) as established by the European guidelines on SCC [39]. Although the reference mix does not fulfill this viscosity class, it is in the range for a high powder content SCC mix, as proposed by Hunger [35]. In addition, no segregation or blocking was observed for any mixes. A long V-funnel time was already reported

Table 3

Properties of the prepared SCC mixes in fresh state.

\begin{tabular}{llll}
\hline Value & Reference & Colloidal $\mathrm{nS}$ & Powder $\mathrm{nS}$ \\
\hline Slump flow $(\mathrm{mm})^{\mathrm{b}}$ & $690-720$ & $664-701$ & $685-720$ \\
V-funnel time $(\mathrm{s})$ & 35.0 & 20.5 & 24.5 \\
Fresh density $\left(\mathrm{g} / \mathrm{cm}^{3}\right)$ & 2.399 & 2.384 & 2.392 \\
Air content $(\% \mathrm{~V})^{\mathrm{a}}$ & 1.15 & 1.79 & 1.58 \\
Packing density $(\%)^{\mathrm{a}}$ & 83.55 & 82.91 & 83.12 \\
\hline
\end{tabular}

a Calculated value.

b Maximum and minimum flow diameter measured. as a typical characteristic of SCC with increased amount of limestone powder [56-58].

As also can be seen in Table 3, the mixes with nano-silica have higher air content compared to the reference mix, which is caused by the higher viscosity of the paste due to the application of particles with high specific surface area (SSA). The assumed air entrainment was also confirmed by comparing the difference between the designed and the measured concrete density (see Tables 2 and 3 ).

\subsection{Hardened concrete: mechanical properties}

\subsubsection{Compressive strength}

The 1-day compressive strength of the reference mix was higher than the strength of mixes with nano-silica (Fig. 2a). At this age, the mix with powder-type nano-silica showed the lowest compressive strength. This behavior can be related to the difference in the reactivity of both nano-silica used. The colloidal nano-silica is synthesized at a low temperature and has a higher concentration of silanol groups on its surface (around $5.3 \mathrm{Si}-\mathrm{OH}$ / $\mathrm{nm}^{2}$ ), which increases its reactivity $[59,60]$. On the contrary, the pyrogenic type of nano-silica has a concentration of silanol groups on its surface in the range of $1.2-2.5 \mathrm{Si}-\mathrm{OH} / \mathrm{nm}^{2}$ [59]. It was demonstrated in [9] that the reactivity of nano-silica is controlled by its specific surface area and the amount of $Q^{2-3}$ (silanol) $\mathrm{Si}-\mathrm{OH}$ groups, which cover the nano-particle. These groups constitute condensation sites for monomeric silica units released from the clinker phases and, consequently, the setting of the cement paste is accelerated. Some researchers reported a strong and instantaneous interaction between nano-silica (independently from its state: colloidal, powder or in slurry) and some chemical species dissolved in the liquid phase of fresh cement pastes, leading to
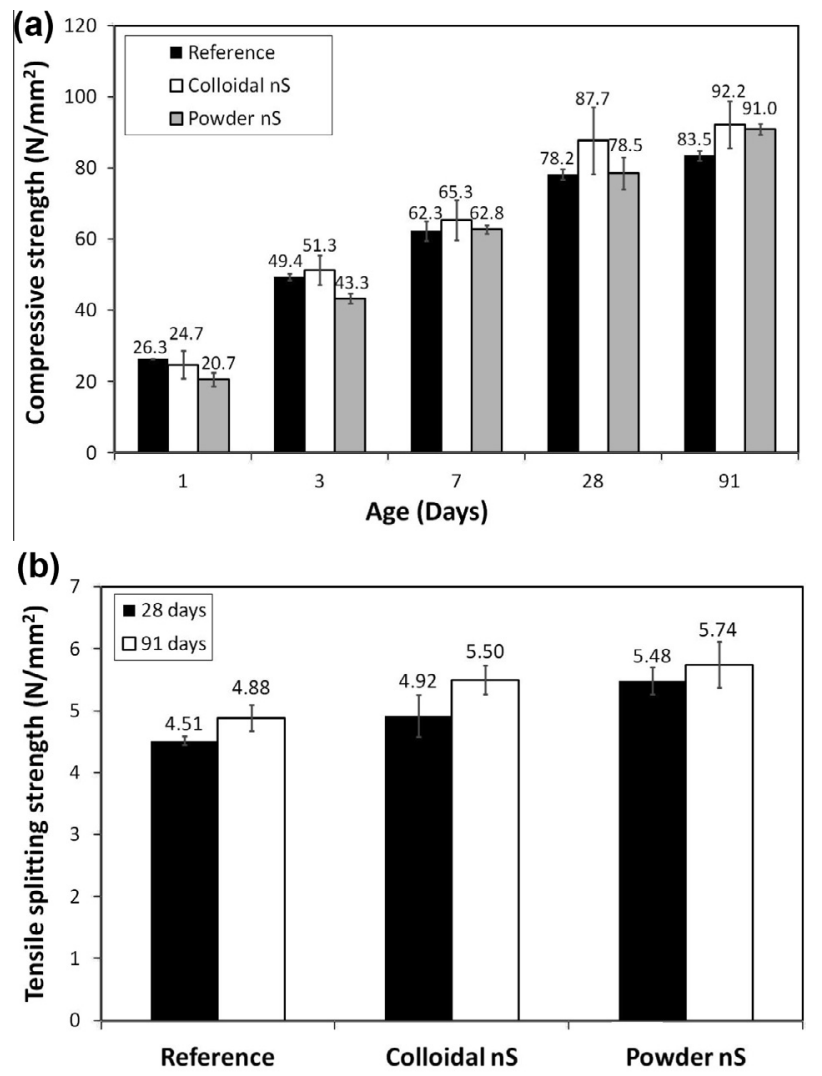

Fig. 2. Mechanical properties of the tested SCC mixes, (a) compressive strength development and (b) 28 and 91 days splitting tensile strength. 
the formation of a destabilizing gel with high water retention capacity (in form of bound water) [61-63]. Even in a well-dispersed colloidal dispersion, the nano-particles still exist as clusters (agglomerates) when incorporated into the highly alkaline environment such as the cement pastes [64]. By using colloidal silica, it is assumed that the mono-dispersed nano-silica can act as filler and seed to form $\mathrm{C}-\mathrm{S}-\mathrm{H}$ gel much more effectively than the agglomerates of silica particles generated from pyrogenic silica powders. Nevertheless, Kong et al. [64] revealed that the colloidal silica reacts to form a gel or coagulates immediately when the cement is mixed in water containing sol due to the rapid increase of ionic strength in the paste, the rising $\mathrm{pH}$ and the adsorption of $\mathrm{Ca}^{2+}$ ions on the silica particles. As a result, no matter which source of nano-silica is used, it is the behavior of the final agglomerates, rather than that of the individual nano-particles, which controls the flowability, the filling ability, the pozzolanic and acceleration effects on the cement hydration and the improvement of the final concrete microstructure.

During the development of strength over time, the mix with colloidal nano-silica showed the highest increase in the compressive strength from 3 until 91 days. An interesting observation is that at 7 days, the mix with powder nano-silica shows similar compressive strength as the reference mix, as the result of a pozzolanic reaction with $\mathrm{Ca}(\mathrm{OH})_{2}$ generated during the OPC hydration. At 91 days, the powder nano-silica developed a higher compressive strength than the reference SCC. In the case of the SCC with colloidal nano-silica, the 91 days compressive strength was almost the same as at 28 days. This fact is mainly caused by the higher reactivity of that silica, so in turn it was consumed earlier. It can be deduced from various investigations $[23,26,29,65]$ that concretes made with nano-silica have a finer pore structure, with a lower proportion of fairly coarse capillary pores. For the same composition, these concretes are, therefore, generally denser than pure Portland cement concretes. One reason for this is a lower content of coarse $\mathrm{Ca}(\mathrm{OH})_{2}$ crystals in the matrix and the aggregate surface zones of these concretes. A shift of the pore structure towards finer pores as a result of the pozzolanic reaction, is also observed when nano-silica is used in concrete $[6,13,23-26,65]$. The reaction of the coarse $\mathrm{Ca}(\mathrm{OH})_{2}$ crystals to form microcrystalline $\mathrm{C}-\mathrm{S}-\mathrm{H}$ phases is recognized to be the cause of this densification of the microstructure. In addition, several researchers reported that concretes with very fine pozzolans, such as nano-silica, have significantly higher impermeability than conventional concretes. This is attributed in particular to a considerable improvement of the aggregate's interfacial transition zone (ITZ) $[6,65,66]$. In normal concretes there is an increased concentration of well crystallized $\mathrm{Ca}(\mathrm{OH})_{2}$ and ettringite needles aligned uniformly towards the aggregate surface in the ITZ, which increases the porosity when compared to the surrounding matrix. Pozzolans that are substantially finer than cement improve the packing of particles at the aggregate surface from the outset, which also favors the pozzolanic reaction in this zone, i.e. the formation of denser and high stiffness $\mathrm{C}-\mathrm{S}-\mathrm{H}$ phases $[6,13,67]$. The changes in the microstructure in the presence of both types of nano-silica are responsible for the slightly increased compressive strength (about 10\% higher) of SCC. A further explanation and support is presented in Section 3.4.

An important factor to take into account is that the 28-day compressive strength results are statistically close between all the mixes. The average compressive strength values for all SCCs lay within the error band of the measurements. The error (standard deviation) in the compressive strength results is higher for the SCC with colloidal nano-silica additions $\left( \pm 9.4 \mathrm{~N} / \mathrm{mm}^{2}\right)$, including the 91-days strength standard deviation $\left( \pm 6.5 \mathrm{~N} / \mathrm{mm}^{2}\right)$. The standard deviations for the reference and powder SCC amount to \pm 1.6 and $\pm 4.5 \mathrm{~N} / \mathrm{mm}^{2}$, respectively. The standard deviations for the nano-silica SCC are higher than the recommended range
(3.5-4.8 N/mm ${ }^{2}$ ) for high strength concrete according to [68]. This could be caused by the increased reactivity and the higher viscosity of the paste, due to the fact that colloidal silica leads to an inhomogeneous dispersion of the mix components. From the industrial point of view it would be a factor to consider in the application of colloidal nano-silica in the future. Higher standard deviation of the 28-day compressive strength should produce SCC mix with "poor" standard of control classification in real conditions [68], based on the fact that higher standard deviations are expected in the field than in the laboratory conditions.

\subsubsection{Tensile splitting strength}

The determined average 28 days tensile splitting strength of the reference mix was $4.51 \mathrm{~N} / \mathrm{mm}^{2}$. The equivalent values for the mixes with colloidal and powder nano-silica are higher and amount to $4.92 \mathrm{~N} / \mathrm{mm}^{2}$ and $5.48 \mathrm{~N} / \mathrm{mm}^{2}$, respectively (Fig. 2b). A possible explanation for the higher tensile splitting strength of the samples containing nano-silica is that the bond between the hardened paste and the aggregates is stronger. The nano-silica improves the quality of the interfacial zone (ITZ) due to precipitation of smaller and stronger (higher stiffness) $\mathrm{C}-\mathrm{S}-\mathrm{H}$ gel and an accelerated rate of hydration of the paste, as it is also reported by several researchers [6-20,65-67]. Similar trends in the tensile splitting strength at 91 days were observed. Further data are presented in Section 3.4. The distinctions on the tensile splitting strength produced by the colloidal nano-silica and the powder nano-silica originate from their different reactivities. As the powder nano-silica is less reactive at early age, a better wet packing or filling of the space between the aggregates is obtained due to a lower viscosity of the paste. Then, with the age and the progress of the pozzolanic reaction, the ITZ is densified, improving the bonding between the matrix and the aggregates. Nevertheless, similarly to the compressive strength results, the average tensile splinting strength values of the SCCs with both types of nano-silica are within the error band of the measurements. It is only evident at 91 days that the compressive and tensile splitting strength of the SCC are improved by $13-18 \%$ due to the use of both types of nano-silica. In the case of the standard deviation values obtained for all the SCC in the tensile splitting strength, all of them are lower than the maximum recommended value of $\pm 0.40 \mathrm{~N} / \mathrm{mm}^{2}$ to be classified as a "good" standard control according to [68].

\subsection{Hardened concrete: durability}

\subsubsection{Permeable porosity}

The results of the measurements of the permeable porosity of the SCC mixes are presented in Table 4. These results are surprisingly showing that the SCC reference mix has slightly lower total porosity $(12.1 \%)$ compared to the mixes containing the two types of nano-silica (12.5\%). The porosity and the tortuosity of the pores in the hardened cement paste are normally reduced when pozzolanic materials are added, and this influences many properties such as the compressive and splitting tensile strength [69]. Nevertheless, Yogendran and Langan [70] stated that for the addition of micro-silica the total pore volume is not necessarily changed, but larger pores appear to be subdivided into smaller pores. Apparently, the same behavior was found for the SCC in the present case. The air content of the fresh mix influenced, probably, the final porosity. Some researchers [43] state that the vacuumsaturation technique is also able to take into account the volume of the entrapped air voids. This means that the porosity values shown Table 4 consider also the differences in the air content of the mixes (the lower the air content the lower the permeable porosity). 
Table 4

28-day permeable porosities and penetration depths of water under pressure of the three designed SCC mixes.

\begin{tabular}{lccc}
\hline Properties & Reference & Colloidal nS & Powder nS \\
\hline Permeable porosity (\% vol.) & $12.07 \pm 0.17$ & $12.45 \pm 0.26$ & $12.48 \pm 0.23$ \\
$\begin{array}{c}\text { Penetration depth of WUP } \\
(\mathrm{mm})\end{array}$ & $26 \pm 7$ & $3 \pm 2$ & $3 \pm 2$ \\
& & & \\
\hline
\end{tabular}

a WUO: water under pressure (5 bar).

\subsubsection{Penetration of water under pressure}

The test results of the penetration of water under pressure are shown in Table 4. According to [29], all tested samples are in the low permeability range (penetration depth of less than $30 \mathrm{~mm}$ ). Additionally, the two SCC with both types of nano-silica presented penetration depth lower than $5 \mathrm{~mm}$. This implies that the addition of $3.8 \%$ nano-silica results in concrete which is highly resistant to the penetration of water under pressure of $0.5 \mathrm{MPa}$ ( 5 bar). Similar permeability improvements were reported by Raiess-Ghasemi et al. [29] for conventional concrete with micro and nano-silica addition. The results also suggest that, despite the similar permeable porosity of all SCC mixes, the nano-silica samples have very low effective water permeability (less interconnected pores and/ or finer pore structure). A similar phenomenon was already reported by Yogendran and Langan [70] for HPC with micro-silica addition, where the total porosity was not affected, but the permeability decreased by one order of magnitude.

\subsubsection{Pore size distribution and porosity of the concrete matrix}

To support the findings presented in Sections 3.3.1 and 3.3.2 the hardened mortar (matrix) of the concrete samples was analyzed
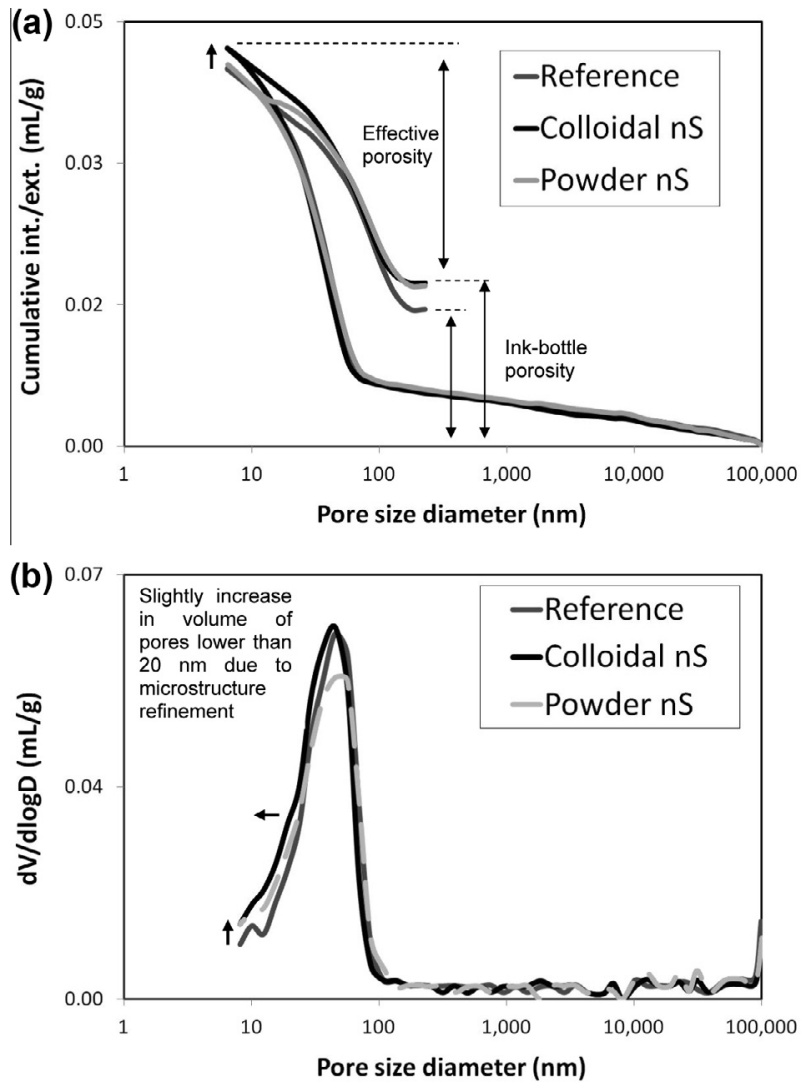

Fig. 3. Mercury intrusion porosimetry results of hardened paste extracted from the tested SCC mixes, (a) cumulative intrusion/extrusion vs. pore size curves, (b) log differential intrusion vs. pore size curves. Black arrows in the figures indicate changes or displacement of the curves due to the addition of nano-silica.
Table 5

Properties of the hardened matrix (mortar) of SCC mixes obtained from MIP measurements.

\begin{tabular}{llll}
\hline Properties & Reference & $\begin{array}{l}\text { Colloidal } \\
\mathrm{nS}\end{array}$ & $\begin{array}{l}\text { Powder } \\
\mathrm{nS}\end{array}$ \\
\hline Median pore diameter (volume) $(\mathrm{nm})$ & 34.8 & 30.9 & 33.8 \\
Median pore diameter (area) $(\mathrm{nm})$ & 20.3 & 17.2 & 17.5 \\
Average pore diameter $(4 \mathrm{~V} / \mathrm{A})(\mathrm{nm})$ & 27.8 & 24.3 & 25.9 \\
Bulk density (at 0.1 $\mathrm{MPa})(\mathrm{g} / \mathrm{ml})$ & 2.216 & 2.222 & 2.239 \\
Apparent (skeletal) density ${ }^{\mathrm{a}}(\mathrm{g} / \mathrm{ml})$ & 2.415 & 2.438 & 2.445 \\
Porosity $(\%)$ & 8.79 & 9.31 & 8.99 \\
\hline
\end{tabular}

a Determined excluding the $\mathrm{Hg}$ accessible pores.

using mercury intrusion porosimetry (MIP). The obtained results are shown in Fig. 3 and Table 5. In Fig. 3a and b it is possible to notice that the addition of $3.8 \%$ of nano-silica slightly increases the volume of pores lower than $20 \mathrm{~nm}$ (indicated by black arrows in Fig. 3a and b). Similar trends were obtained for the overall parameters that were extracted from the mercury intrusion test. These parameters are shown in Table 5. It is clearly shown in this table that the addition of nano-silica decreased the median pore diameter (by volume and area) and the average pore diameter, which is reduced from $27.8 \mathrm{~nm}$ (for the reference) to 24.3 and $25.9 \mathrm{~nm}$ for the colloidal nano-silica and powder nano-silica, respectively. Apparently, a reduction of $4 \mathrm{~nm}$ in the average pore diameter was enough to significantly reduce the permeability of the SCC containing nano-silica. According to Mindess et al. [71], the pores in cement paste are divided into large capillary pores (10$0.05 \mu \mathrm{m})$, medium capillary pores $(50-10 \mathrm{~nm})$ and gel pores $(<10 \mathrm{~nm})$. This means that the modification of the SCC pore structure due to nano-silica addition is reflected by the changes in the medium capillary pores and the gel pores (the minimum pore size detected with MIP was $8 \mathrm{~nm}$ ). Permeability and penetration of harmful substances into concrete are affected mainly by the large and medium capillary pores [68]. Apparently, nano-silica made the pore structure of paste more homogeneous by increasing medium capillary porosities. In similar way, the gel pores volume was increased (see Fig. 4). The increased gel porosity can be caused by an increased amount of $\mathrm{C}-\mathrm{S}-\mathrm{H}$ gel in the paste (acceleration effect of the nano-silica [9]). The increased gel porosity could result from a higher hydration degree and from the properties of the gel produced by the pozzolanic reaction of the nano-silica particles. Pozzolanic C-S-H gels, normally, have a lower $\mathrm{Ca} / \mathrm{Si}$ ratio (1-0.8) and different gel porosities [72]. Similar changes in the pore structure of blended cement with slag and nano-silica addition were reported in [66].

Another interesting fact, also presented in Table 5, is that the apparent (skeletal) density of the hardened mortar was higher for the SCC with nano-silica (both types). This demonstrates that the addition of nano-silica promotes the densification of the cement matrix. Despite this densification, the apparent porosity of paste increases with the addition of nano-silica (see Table 5), similarly to the results obtained for the permeable porosity of SCC. This means that other factors are improving the resistance to water penetration of the SCC with nano-silica. These factors can be e.g. changes of the shape of pores (cylindrical vs. bottle-neck type), changes of the tortuosity or pores interconnectivity and an improvement of the ITZ of cement paste/aggregates. During the intrusion cycles, the complete pore space is filled with mercury. When the pressure is released, the mercury is sucked out of the pore space except for the ink-bottle and dead-end pores. Isolated (non-accessible) pores do not contribute to the transport properties of fluids and cannot be detected by MIP. Nevertheless, taking into account the differences between the intrusion and the extrusion cycles of mercury (Fig. 3a) and the definition of effective 

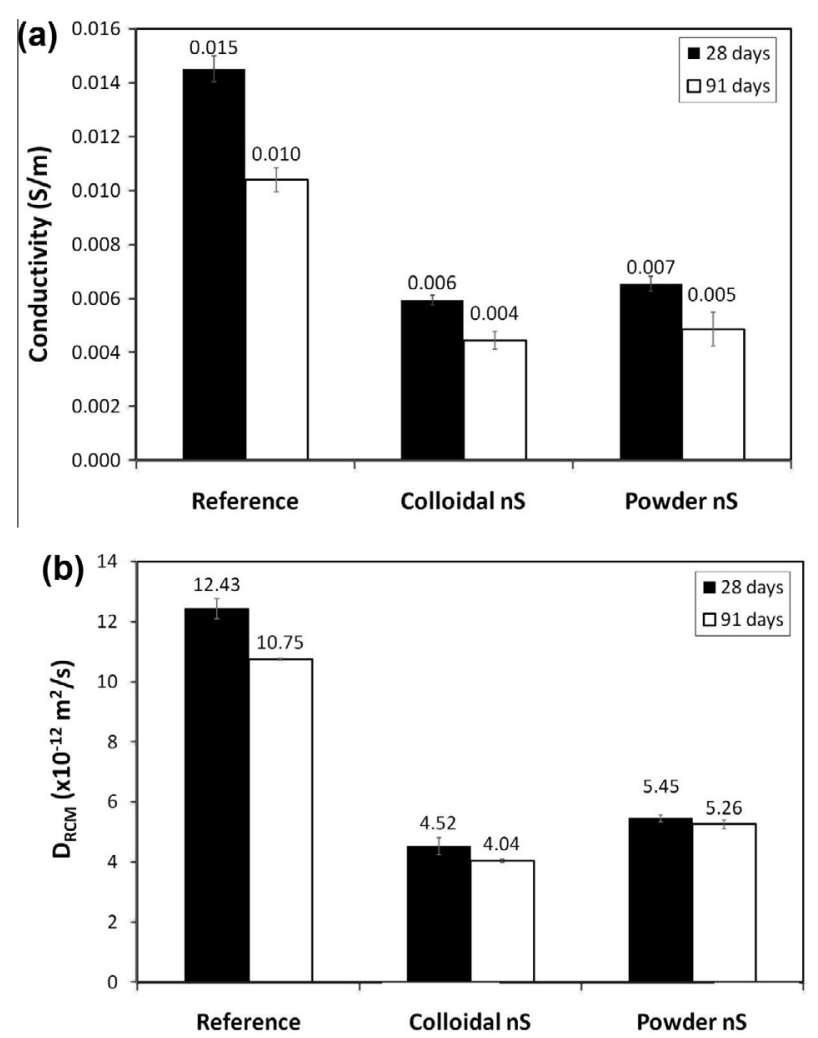

Fig. 4. 28 and 91 days test results: (a) conductivity and, (b) chloride migration coefficient $\left(D_{\mathrm{RCM}}\right)$.

porosity and ink-bottle porosity defined in [73], it is possible to observe that the addition of nano-silica increased the amount (volume) of ink-bottle pores. The increment is around $7 \%(+0.0028 \mathrm{ml} /$ $\mathrm{g})$ for both types of nano-silicas. The transport of species through the ink-bottle pores is more difficult due to their constrictivity. These differences can explain the changes observed in the pores structure of the cement pastes and can partially explain the results of water pressure penetration test. Similar results were reported by Shih et al. [74] who found a small difference in the porosity $(2.84 \%$ in the volume of pores of cement pastes with nano-silica compared to pure cement pastes), but they demonstrated that nano-silica addition of $0.8 \%$ (based on the weight of cement) caused that the microstructure of hardened cement becomes denser in the regions where the pore size was larger than $10 \mathrm{~nm}$, but becomes looser at regions where the pore size is smaller than $10 \mathrm{~nm}$. Even though, the performed MIP analysis gives some evidence of the changes in the concrete pore structure, the results are close to the repeatability band of the test. For that reason, complementary pore size distribution analyses and other characterization techniques enabling to detect changes in the pore structure are recommended in further research.

\subsubsection{Conductivity}

Fig. 4a shows the average values of the conductivity, measured on cylindrical SCC samples that were extracted from the cast cubes. It is clearly shown that the conductivity of the SCC with nano-silica addition is reduced by more than $50 \%$ compared to the SCC reference mix. Meanwhile, the SCC with the colloidal nano-silica presented a slightly lower conductivity than samples with the powder nano-silica. This behavior is an indication of the ability of the water-saturated pore structure of the concrete to transport electrical charge. Different authors [75-77] established that the conductivity is directly related to the porosity, the pore structure (tortuosity, connectivity and conductivity) and to the $\mathrm{pH}$ of the pore solution (the $\mathrm{pH}$ in the presence of amorphous silica is decreased, as was established in [47]). In general, more pore water as well as more and larger pores with higher degree of connectivity and lower tortuosity results in higher electrical conductivity values [48]. The lower conductivity values shown by the SCC with nanosilica are the result of the pore structure refinement (less connected pores) due to the progressive pozzolanic reaction and higher hydration degree (see the microstructural analysis section). The small difference between the two types of silica is mainly related to the higher reactivity of the colloidal nano-silica, which promotes a more compact and finer microstructure (higher stiffness $\mathrm{C}-\mathrm{S}-\mathrm{H}$ gel) than the powder nano-silica. Nevertheless, the values are in line with the results of the penetration of water under pressure and the determined compressive strength. Conductivity or its inverse value (resistivity) can also be related to the compressive strength as it was demonstrated by Andrade et al. [76]. These authors concluded that the electrical resistivity is a suitable test for providing the estimated compressive strength with a high level of reliability. The resistivity is related with the compressive strength because it reflects the ability of the porous medium to transfer the electrical charge thought the aqueous phase. This property promotes the satisfactory relation between the resistivity, porosity and connectivity of pores in saturated concrete. Due to the refinement of the pore structure (progressive hydration during time), the resistivity increases over time. It was demonstrated [76] that this evolution is very similar to the development of the compressive strength in time, and a linear relationship between the compressive strength and the resistivity was proposed. Nevertheless, the improvements in the compressive strength of the SCCs were much lower than the improvement obtained in the conductivity test. This is probably due to the fact that the total pore volume of the SCC is not reduced by the pozzolanic reaction promoted by the nano-silica additions, but the pore structure becomes more discrete. In addition, the electrical conductivity of concrete depends on the pore solution chemistry and chemical binding of various ions by the hydration products [78], whereas these phenomena do not affect the strength. The use of nano-silica dilutes the pore solution and increases the binding of different ions such $\mathrm{Na}^{+}$and $\mathrm{K}^{+}$by the reaction products. Consequently, the $\mathrm{pH}$ of the pore solution is reduced $\left(\mathrm{OH}^{-}\right.$concentration drop). Because the important role of hydroxyl ions in the conductivity of concrete, the reduction of the $\mathrm{pH}$ of the pore solution of concrete due to the use of supplementary cementitious materials such as nano-silica can increase the electrical resistance of concrete [78].

\subsubsection{Rapid chloride migration test (RCM)}

The Rapid chloride migration test (performed according to NT Build 492 [46]) is a commonly used accelerated technique for determining the chloride transport rate in concrete. The output of the test - the so-called chloride migration coefficient $D_{\mathrm{RCM}}$ - can be employed in service-life design models for concrete elements and structures exposed to chlorides. In this context, Fig. $4 \mathrm{~b}$ presents the average values of the calculated chloride migration coefficients $\left(D_{\mathrm{RCM}}\right)$ of each SCC mix studied. Like the conductivity test results, the migration coefficients are much lower for the mixes containing nano-silica. Additionally, the SCC mix with colloidal nano-silica shows again the best performance. The explanation of this behavior is the same as previously discussed for the conductivity test results. A finer porosity, greater tortuosity and more precipitated $\mathrm{C}-\mathrm{S}-\mathrm{H}$ gel reduce the ingress speed of chlorides into the concrete. It can also be noticed that the 91 days $D_{\mathrm{RCM}}$ values are lower compared to the 28 days $D_{\mathrm{RCM}}$. This can be explained by the progressing hydration of cement and a related densification of the microstructure of concrete. 
Table 6

Maximum values of 28-days $D_{\mathrm{RCM}}$ coefficients for 100 years of service-life design of concrete, taken from [72].

\begin{tabular}{|c|c|c|c|c|c|c|c|c|c|}
\hline \multicolumn{2}{|c|}{$\begin{array}{l}\text { Minimum concrete cover } \\
\text { depth }(\mathrm{mm})\end{array}$} & \multicolumn{8}{|c|}{ Maximum value of $D_{\mathrm{RCM}}\left(\times 10^{-12} \mathrm{~m}^{2} / \mathrm{s}\right)$} \\
\hline \multirow[t]{2}{*}{ Steel } & \multirow[t]{2}{*}{ Pre-stressed steel } & \multicolumn{2}{|l|}{ CEM I } & \multicolumn{2}{|c|}{ CEM I + CEM III 25-50\% GGBS } & \multicolumn{2}{|l|}{ CEM III 50-80\% GGBS } & \multicolumn{2}{|c|}{$\begin{array}{l}\text { CEM II B/V + CEM I 20-30\% fly } \\
\text { ash }\end{array}$} \\
\hline & & $\mathrm{XD} 1, \mathrm{XD} 2, \mathrm{XD} 3, \mathrm{XS} 1$ & $\mathrm{XS} 2, \mathrm{XS} 3$ & XD1, XD2, XD3, XS1 & $\mathrm{XS} 2, \mathrm{XS} 3$ & XD1, XD2, XD3, XS1 & $\mathrm{XS} 2, \mathrm{XS} 3$ & XD1, XD2, XD3, XS1 & $\mathrm{XS} 2, \mathrm{XS} 3$ \\
\hline 35 & 45 & 3.0 & 1.5 & 2.0 & 1.0 & 2.0 & 1.0 & 6.5 & 5.5 \\
\hline 40 & 50 & 5.5 & 2.0 & 4.0 & 1.5 & 4.0 & 1.5 & 12 & 10 \\
\hline 45 & 55 & 8.5 & 3.5 & 6.0 & 2.5 & 6.0 & 2.5 & 18 & 15 \\
\hline 50 & 60 & 12 & 5.0 & 9.0 & 3.5 & 8.5 & 3.6 & 26 & 22 \\
\hline 55 & 65 & 17 & 7.0 & 12 & 5.0 & 12 & 5.0 & 36 & 30 \\
\hline 60 & 70 & 22 & 9.0 & 16 & 6.5 & 15 & 6.5 & 47 & 39 \\
\hline
\end{tabular}

The 28-day $D_{\mathrm{RCM}}$ can be employed in service-life design models $[79,80]$ for concrete elements and structures exposed to chlorides. When comparing all the obtained 28-day $D_{\mathrm{RCM}}$ to the values suggested in the CUR Durability Guideline [80] for 100 years of service life (see Table 6), the SCC reference mix is out of the range of the aimed exposure class XS3. In contrast, both SCC mixes with nano-silica addition satisfy the exposure class XS3 when a concrete cover depth of $50 \mathrm{~mm}$ is provided. This demonstrates how a relatively small addition of the nano-silica (3.8\% based on the weight of cement) can effectively increase the resistance of concrete to the intrusion of chlorides, and opens, therefore, a possibility for reducing the thickness of the concrete cover, based on the values suggested in [80], which are shown in Table 6. On the other hand, comparing the obtained $D_{\text {RCM }}$ values to similar SCC mixes published in literature, the values obtained for the reference mix are in line with SCC mixes having high amount of limestone powder (between 8 and $12 \times 10^{-12} \mathrm{~m}^{2} / \mathrm{s}$ at 28 days [22]). The values obtained for the SCC mixes with nano-silica are comparable to reported values of SCC composed of slag cement or fly ash with similar $w / b$ ratio and cement content (between 4 and $\left.5 \times 10^{-12} \mathrm{~m}^{2} / \mathrm{s}[22]\right)$.

\subsubsection{Chloride diffusion test}

In Fig. 5a the obtained apparent chloride diffusion coefficients $\left(D_{\text {app }}\right)$ of the three SCC mixes are shown. A trend similar to the $D_{\mathrm{RCM}}$ was obtained for the diffusion test. The largest $D_{\text {app }}$ was computed for the reference SCC, $9.61 \times 10^{-12} \mathrm{~m}^{2} / \mathrm{s}$. The $D_{\text {app }}$ of $4.45 \times 10^{-12} \mathrm{~m}^{2} / \mathrm{s}$ and $3.55 \times 10^{-12} \mathrm{~m}^{2} / \mathrm{s}$ were obtained for powder nano-silica and colloidal nano-silica, respectively. Even though the chemical balance of the pore solution is changed due to the addition of nano-silica and the dominating chloride transport mechanisms in both methods are different (migration due to the electrical field and diffusion due to the concentration gradient), the obtained $D_{\text {app }}$ and $D_{\mathrm{RCM}}$ have comparable values for each tested SCC.

\subsubsection{Freeze-thaw resistance}

The results of the freeze-thaw surface scaling of the three selected SCC mixes are shown in Fig. 5b. The failure of the SCC reference mix, taking into account the maximum scaling criteria of $1.5 \mathrm{~kg} / \mathrm{m}^{2}$ at 28 cycles as recommended in [81], occurred about the 11th cycle. On the other hand, the SCC mixes with nano-silica addition resulted in a surface scaling factor lower than the recommended value for non-air entrained concrete after 28 cycles. These SCC mixes failed the $1.5 \mathrm{~kg} / \mathrm{m}^{2}$ criteria after 48 cycles. The freezethaw resistance depends on the compressive strength, porosity, air void content and other parameters such as the air-voids distribution and pore size [68]. A better resistance to the freeze-thaw induced damage of the SCC with nano-silica addition can be attributed to different factors, such as the formation of highly stiff $\mathrm{C}-\mathrm{S}-\mathrm{H}$
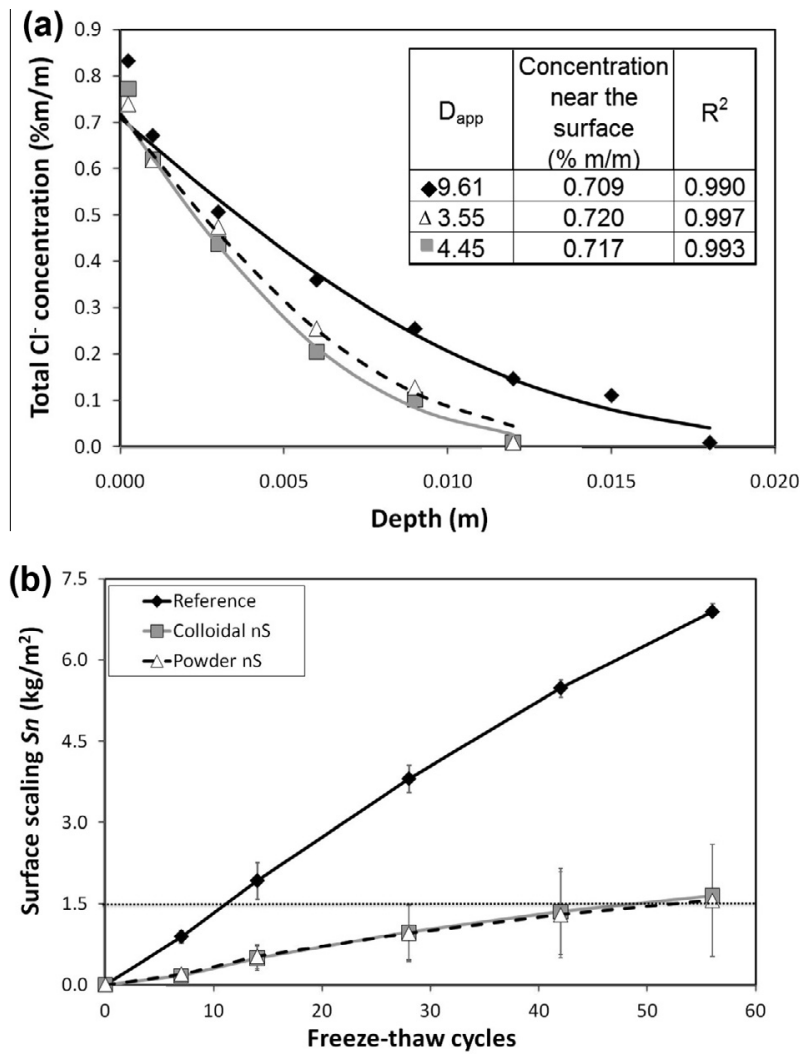

Fig. 5. (a) Chloride diffusion profiles of the tested SCC mixes, (b) cumulative scaling factor ( $\mathrm{Sn}$ ) after 56 freeze-thaw cycles (3\% $\mathrm{NaCl}$ solution).

gel (with $E$ modules of $26 \mathrm{GPa}$ reported by [67]) and the refined pore structure (higher tortuosity and constrictivity of the pores), which results in a limited intrusion of water and improved resistance to the changes of temperature near the surface of the concrete. Despite the better freeze-thaw resistance of the SCC with nano-silica compared to the reference mix, its scaling values are larger than the recommended value of $0.5 \mathrm{~kg} / \mathrm{m}^{2}$ after 56 cycles, suggested by Stark and Wicht [82] for a concrete classified as having good resistance against freeze-thaw exposure. Nevertheless, with an air entrainment admixture that guarantees a minimum air content of $4 \%$, the freeze-thaw resistance of SCC with nano-silica should result in a mix having a high resistance to freeze-thaw.

\subsection{Microstructural analysis}

The objective of the microstructural analysis is to support the findings shown in the previous sections. It is important to notice, 
that the performed microstructural analyses were qualitative, with the objective to give additional information that can explain the results obtained in the other executed tests. In this context, Fig. 6 shows some selected morphological characteristics of the microstructure of the SCC reference mix. The SCC reference mix has an apparent dense structure and a relatively good ITZ (Fig. 6a). A good ITZ is defined in the present investigation as the zone $(10-20 \mu \mathrm{m}$ long) in the vicinity of the sand and gravel aggregates, with a relatively lower amount of gel and air pores. The microstructure presented heterogeneous morphologies, with high amounts of small pores and big sized C-S-H gel like structures. Additionally, acicular (needle-shaped) structures (Fig. 6b) were identified and possibly formed of ettringite or other AFt phases that are rich in $\mathrm{CO}_{3}^{-2}$ (verified by EDS). The formation of the needle-shaped AFt phases in cement pastes with a high calcium carbonate concentration was reported in [83]. Another expected phase that was not possible to identify is monocarboaluminate. The influence of the presence of limestone on the hydration of Portland cement was investigated by [84]. Blending of Portland cement with limestone was found to influence the hydrate assemblage of the hydrated cement. Thermodynamic calculations as well as experimental observations indicated that in the presence of limestone, monocarbonate instead of monosulfate was stable. Thermodynamic modelling shows that the stabilisation of monocarbonate indirectly also stabilises ettringite. This leads to a corresponding decrease of the total volume of the hydrated phase and an increase of porosity. Similarly, Bonavetti et al. [85] reported that in limestone-blended cement (20\% limestone based on the weight of cement), calcium monocarboaluminate can be easily detected at 3 days and its amount increases after 28 days of hydration. The excess of carbonate ions in cement paste causes the transformation of monosulfoaluminate to monocarboaluminate. This promotes the reconversion of monosulfoaluminate to ettringite in limestone blended cements due to the sulfates liberated during the carbonate substitution reaction. The conversion of ettringite to monosulfoaluminate is deferred by the presence of limestone filler. Probably, similar hydrates phase assemblies take place in the reference SCC, which has a limestone concentration of $179.4 \mathrm{~kg} / \mathrm{m}^{3}$ (34\% based on the weight of cement). Nevertheless, without complementary characterization techniques such as X-ray diffraction (XRD) and differential thermogravimetric analysis (DTG) it is not possible to confirm the formation of manocarbonates phases in the reference SCC. In addition, in the reference SCC, well crystallized hexagonal portlandite $\left(\mathrm{Ca}(\mathrm{OH})_{2}\right)$ plates were formed in the cement matrix and in the largest air-voids (Fig. 6c) due to the absence of any pozzolanic additives. Normally, the presence of significant amounts of $\mathrm{Ca}(\mathrm{OH})_{2}$ results in a lower chloride intrusion resistance and lower compressive strength [13]. These findings are in line with the mechanical and durability test results discussed previously.

As it can be observed in Fig. 7a, the SCC with colloidal nano-silica shows a more homogeneous microstructure compared to the reference mix. A homogenous microstructure is defined by a more regular morphology and similar size of the hydrates. This microstructure is characterized by apparent compact and small-sized $\mathrm{C}-\mathrm{S}-\mathrm{H}$ gel and the absence of abundant gel porosity. As a consequence, a relatively denser ITZ was also confirmed by SEM (Fig. 7b). It is important to notice, that the needle-type structures or well grown $\mathrm{Ca}(\mathrm{OH})_{2}$ crystals were not found in the microstructural analysis. The absence of needle-type hydrates in the cement matrix is unexpected. In general, as was explained for the reference SCC, ettringite is one of the hydrated phases formed in cement system with high amount of limestone additions. In the case of the SCC with colloidal nano-silica the concentration of limestone was slightly decreased (from 179.4 to $151.8 \mathrm{~kg} / \mathrm{m}^{3}$ ), but this decrease should not influence the hydrates formation. Similarly, in system with amorphous nano-silica it was predicted [72] that one of the stable phases formed is ettringite. Ettringite in long-term is only unstable when the $\mathrm{pH}$ of the pore solution falls below 10 due to further replacement of cement by silica. The dropping of the pore solution $\mathrm{pH}$ to values lower than 10 is predicted for amorphous silica additions higher than $35 \%$ by mass [72]. In the present research only 3.8\% (based on the weight of cement) of nano-silica is added. One possibility that can explain the absence of ettringite is that the addition of nano-silica decreased the size of ettringite crystals, making it much more difficult to be identified by the used magnification of the ESEM. Also, smaller ettringite crystals are more susceptible to be discomposed by drying and vacuum conditions as was reported by [86]. As was mentioned before, well grown $\mathrm{Ca}(\mathrm{OH})_{2}$ crystals were not found in the microstructural analysis.

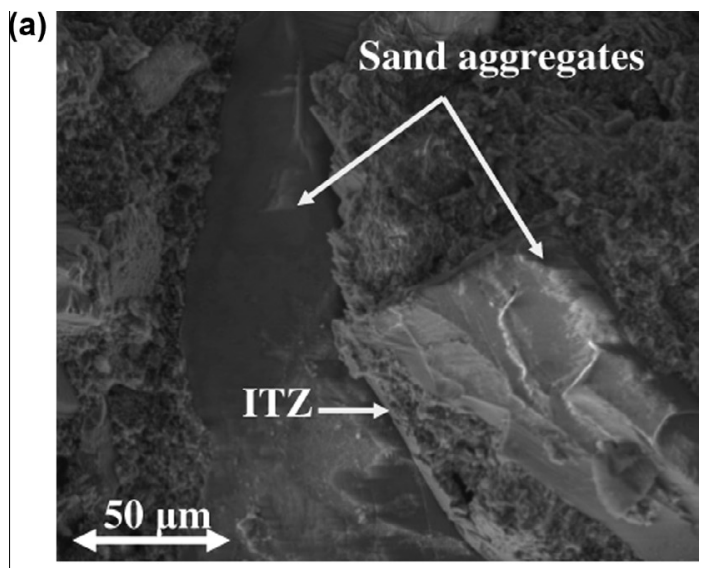

(b)

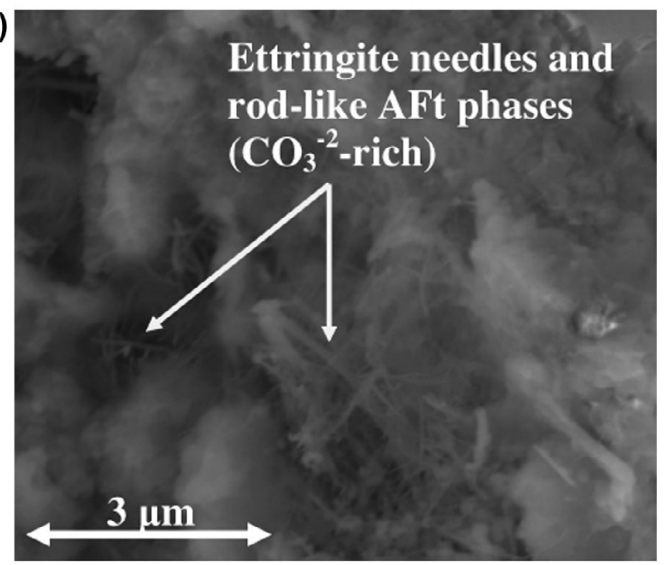

(c)

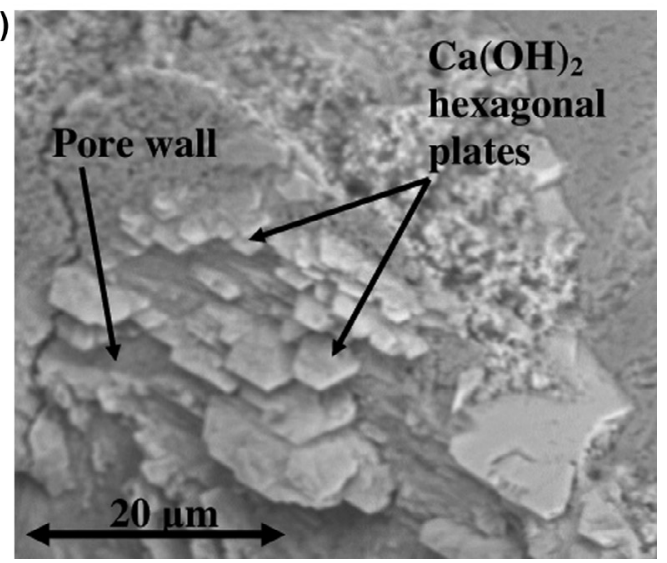

Fig. 6. Microstructure low vacuum (0.6 mbar) FEG-SEM photomicrographs of the SCC reference mix, (a) cement matrix and aggregate ITZ, (b) Ettringite and AFt needles and (c) precipitated hexagonal Portlandite plate crystals. 
Changes in the amount and size of portlandite crystals are expected in the presence of amorphous silica as it was established by different authors [6-20]. The absence of well crystallized portlandite and the lower volumes of gel pores confirm that the addition of the nano-silica causes a refinement of the microstructure and probably induces the precipitation of small-sized $\mathrm{C}-\mathrm{S}-\mathrm{H}$ gel that normally has a high stiffness and lower $\mathrm{Ca} / \mathrm{Si}$ ratio [67]. The improvement of the microstructure is also reflected by the mechanical properties (compressive and splitting tensile strength) due to the fact that the pozzolanic gel structure has better mechanical properties than the $\mathrm{C}-\mathrm{S}-\mathrm{H}$ gel precipitated in OPC concrete. These differences in the local $\mathrm{C}-\mathrm{S}-\mathrm{H}$ gel properties were reported by Mondal et al. [67] using nanoindentation techniques. The study complemented with 29Si MAS-NMR spectra of the cement pastes with nano-silica proved that its addition increases the average chain length of $\mathrm{C}-\mathrm{S}-\mathrm{H}$ gel. Therefore, it is expected that nano-silica increases either the amount of high-stiffness $\mathrm{C}-\mathrm{S}-\mathrm{H}$ gel ( $E$ modulus of $26 \mathrm{GPa}$ ) or the strength of the ITZ. Nanoindentation studies proved that the elastic moduli of the two types of $\mathrm{C}-\mathrm{S}-\mathrm{H}$ phases (low and high stiffness type) did not change with the addition of nano-silica [67]. However, they stated that nano-silica increased the volumetric amount of high-stiffness $\mathrm{C}-\mathrm{S}-\mathrm{H}$ gel. For example, they reported that in samples with $6 \%$ by mass of nano-silica, the volume fraction of high-stiffness $\mathrm{C}-\mathrm{S}-\mathrm{H}$ was as high as $38 \%$ by vol. of the total gel. In contrast, reference samples (without nanoparticles) showed only $19 \%$ by vol. of high stiffness C-S-H gel. (a)

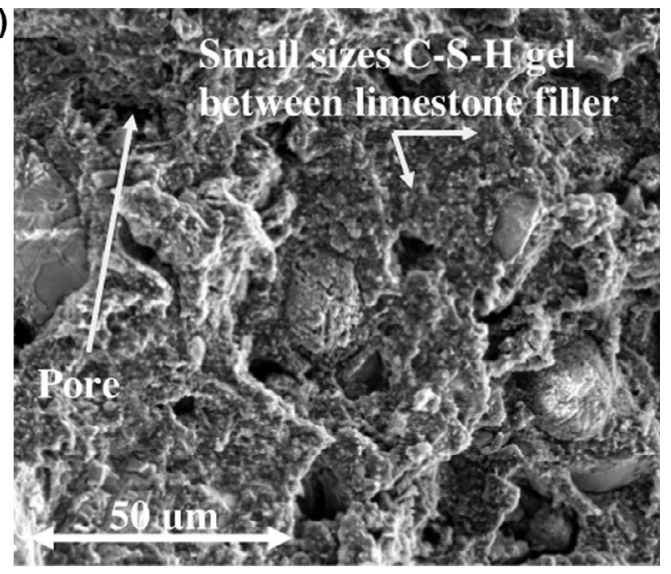

(b)

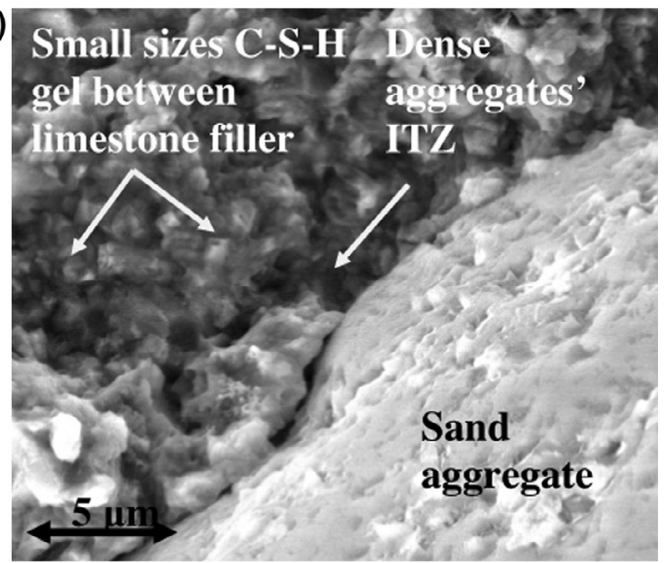

(c)

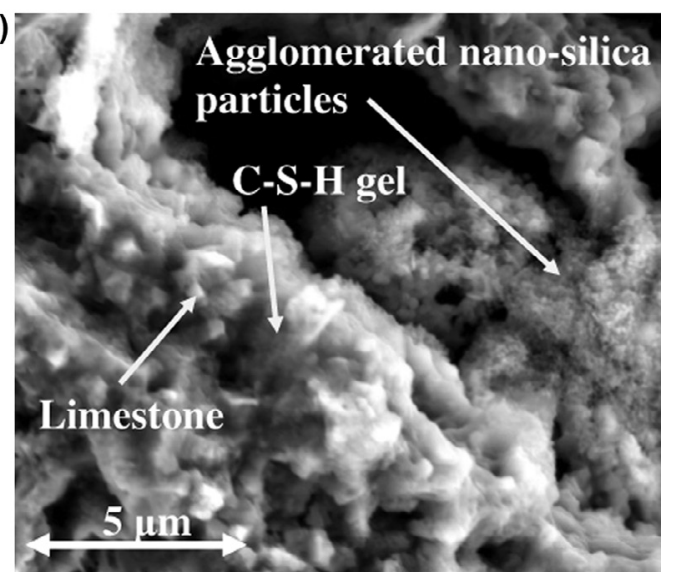

Fig. 7. Microstructure low vacuum (0.6 mbar) FEG-SEM photomicrographs of the SCC colloidal nano-silica mix, (a) cement matrix, (b) aggregate dense ITZ and (c) agglomerates in a pore. (a)

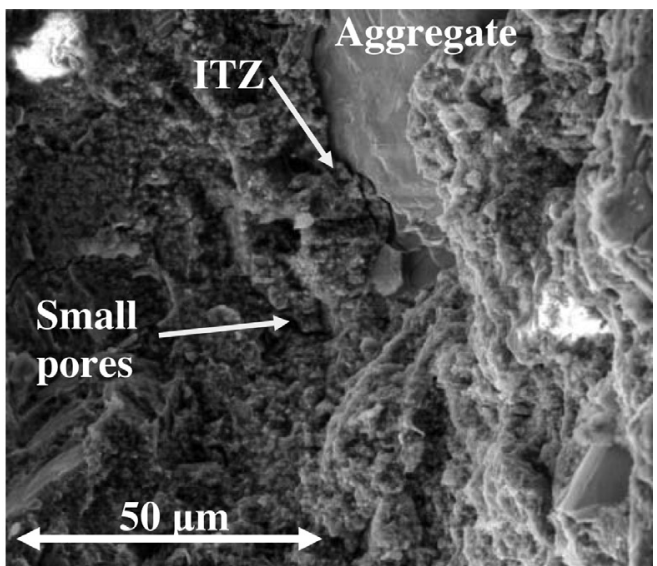

(b)

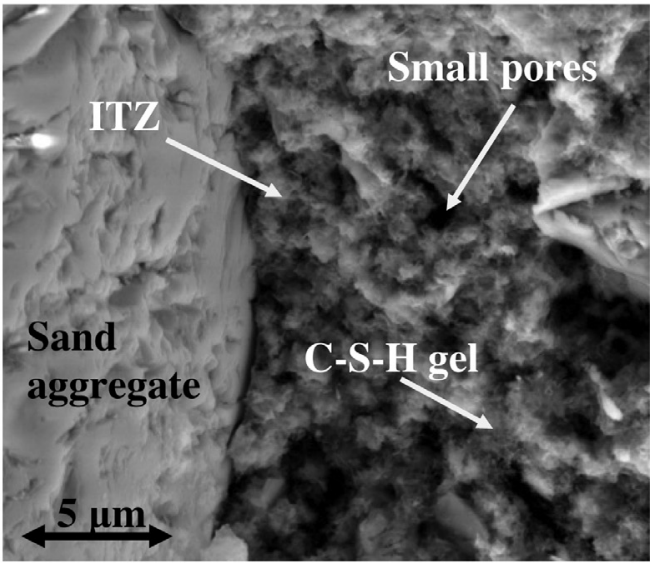

(c)

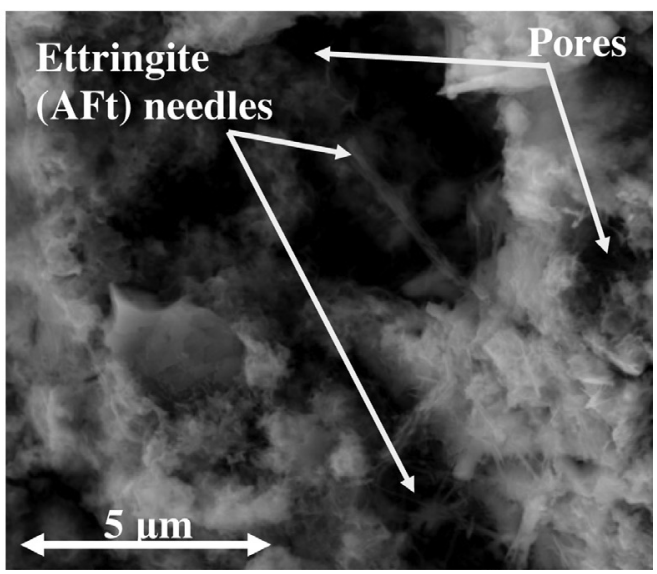

Fig. 8. Microstructure low vacuum (0.6 mbar) FEG-SEM photomicrographs of the SCC powder nano-silica mix, (a) cement matrix, (b) aggregates ITZ and (c) AFt needles precipitates. 
Thus, the increased volume of the high-stiffness $\mathrm{C}-\mathrm{S}-\mathrm{H}$ gel might explain the positive impact of nano-silica on the durability of SCC in the present study.

In the case of SCC with powder nano-silica, the obtained results of the microstructural analysis were similar to the colloidal nanosilica. Its microstructure is also found to be refined (as it is shown in the selected image in Fig. 8a), but not as much as with the colloidal nano-silica. Apparently, due the fact that this nano-silica was produced at high temperature (more compact, lower concentration of silanol groups) its pozzolanic reactivity is lower than the colloidal one. Nevertheless, a relatively homogeneous matrix was observed with more small pores distributed in it (Fig. 8b). Even though the microstructure was refined due to the addition of the powder silica, it was still possible to observe some remnant needle-shaped AFt phases in the matrix (Fig. 8c). As it was explained for the reference and SCC with colloidal nano-silica, the presence of ettringite is expected in blended cements with amorphous silica additions. In the case of the powder nano-silica, the size of the ettringite needle appears to be smaller than the needle-type hydrates identified by the reference SCC. This can confirm that the presence of amorphous nano-silica and probably also the higher amount of SP in the SCC, could modify the morphology of the ettringite-type hydrates. Taylor [86] reported that the amount of available space, $\mathrm{pH}$ and sulfate ion concentration control the ettringite morphology.

In summary, the resistance to the intrusion of chlorides and water under pressure in the SCC containing nano-silica was improved due to the densification of the microstructure and the high specific surface area of the produced gel [49]. The high reactivity of the colloidal nano-silica was also confirmed in Fig. 8c, where small $\mathrm{C}-\mathrm{S}-\mathrm{H}$ gel precipitates were observed around the limestone powder and agglomerates of nano-particles. The differences between the SCC with both types of nano-silica observed in the microstructural analysis can explain the results that were obtained for these two SCCs, where the SCC containing colloidal nano-silica presented better results in most of the performed tests. The SCC with colloidal nano-silica appears to have a denser matrix and ITZ than the SCC with powder nano-silica, leading to a refined microstructure. The refinement of the microstructure was confirmed by the increased volumes of ink-bottle pores in the SCC. In addition, this refinement causes better mechanical and durability properties of the tested SCC. Nevertheless, further research is needed to relate the results obtained in this study with the progressing hydration of the SCC paste in the presence of nano-silica particles. In addition, further research is also needed to determine which type of nano-silica is better for a real scale production of SCC.

\section{Conclusions}

Based on the mechanical and durability properties obtained by the tests on a reference SCC and SCC mixes containing two types of nano-silica, the following conclusions can be drawn:

- The results of the fresh state behavior of SCC demonstrated that concrete with an addition of $3.8 \%$ nano-silica (based on the weight of cement) shows similar flow properties and viscosity as the reference mix without nano-silica. Slightly increased air content in the mixes with nano-silica was measured due to a higher viscosity of the paste.

- Under the laboratory conditions, the compressive and tensile splitting strength of the reference SCC was improved by the addition of both types of nano-silica. The highest compressive strength was found for the colloidal nano-silica, while the highest splitting tensile strength was found for the powder type nano-silica. Small differences in the reactivity at early age (1-day) were confirmed by the compressive strength measurements for both types of nano-silica studied.

- The water permeable porosity of the three SCC mixes was found to be similar. On the other hand, when nano-silica was added, the concrete becomes almost impermeable to the penetration of water under pressure. This can be explained by a refinement of the microstructure of the paste due to higher amount of pores with ink-bottle shape, as confirmed by MIP measurements.

- All durability indicators of the SCC studied (conductivity, chloride migration and diffusion coefficients, and freeze-thaw resistance) were significantly improved with the addition of $3.8 \%$ of both types of the nano-silica. Moreover, the SCC with colloidal nano-silica showed slightly better properties than the SCC with powder nano-silica.

- The microstructural analysis of the hardened SCC reveals that the addition of nano-silica resulted in a homogeneous microstructure, characterized by compact and small-sized $\mathrm{C}-\mathrm{S}-\mathrm{H}$ gel. As a consequence, a denser ITZ was produced. The addition of nano-silica caused a refinement of the microstructure (less interconnected and finer pore structure) and induced the precipitation of small-sized $\mathrm{C}-\mathrm{S}-\mathrm{H}$ gel, probably having a higher stiffness and lower $\mathrm{Ca} / \mathrm{Si}$ ratio.

- The improvement of the microstructure resulted in higher mechanical properties (compressive and splitting tensile strength) due to the fact that the pozzolanic gel structure shows better mechanical properties than the $\mathrm{C}-\mathrm{S}-\mathrm{H}$ gel precipitated in OPC concrete. In addition, permeability of concrete was significantly reduced (good resistance against the penetration of chlorides and water under pressure) because of the microstructural densification and increased tortuosity of the pore system.

- The high reactivity and faster pozzolanic behavior of the colloidal nano-silica particles at early age produced a more refined microstructure than obtained for the SCC with powder nano-silica. Nevertheless, the higher reactivity and agglomerated state appears to be the reason for the higher standard deviation obtained in the compressive strength results.

\section{Acknowledgments}

This research was carried out under the Project Number M81.1.09338 in the framework of the Research Program of the Materials innovation institute (www.m2i.nl) and The European Community's Seventh Framework Program, ProMine: Nano-particle products from new mineral resources in Europe, FP7-NMP2008-LARGE-2 under Grant Agreement 228559. The authors also wish to express their gratitude to the following sponsors of the Building Materials research group at TU Eindhoven: Rijkswaterstaat Grote Projecten en Onderhoud, Graniet-Import Benelux, Kijlstra Betonmortel, Struyk Verwo, Attero, ENCI, Provincie Overijssel, Rijkswaterstaat Zee en Delta - District Noord, A\&G Maasvlakte, BTE, Alvon Bouwsystemen, V.d. Bosch Beton, Selor, Twee "R" Recycling, GMB, Schenk Concrete Consultancy, Geochem Research, Icopal, BN International, APP All Remove, Consensor, Eltomation, Knauf Gips, Hess ACC Systems, Kronos and Joma international (chronological order of joining).

\section{References}

[1] Scrivener KL, Kirkpatrick RJ. Innovation in use and research on cementitious material. Cem Concr Res 2008;38:128-36.

[2] Sanchez F, Sobolev K. Nanotechnology in concrete - a review. Constr Build Mater 2010;24:2060-71.

[3] Constantinides G, Ulm F. The nanogranular nature of C-S-H. J Mech Phys Solids 2007;55:64-90.

[4] Richarson IG. The nature of the hydration products in hardened cement pastes. Cem Concr Compos 2000;22:97-113. 
[5] Nili $\mathrm{M}$, Ehsani A, Shabani $\mathrm{K}$. Influence of nano- $\mathrm{SiO}_{2}$ and micro-silica on concrete performance. In: Proceedings second international conference on sustainable construction materials and technologies, June 28-30, Universita Politecnica delle Marche, Ancona, Italy; 2010.

[6] Qing Y, Zenan Z, Deyu K, Rongshen Ch. Influence of nano- $\mathrm{SiO}_{2}$ addition on properties of hardened cement paste as compared with silica fume. Constr Build Mater 2007;21:539-45.

[7] Senff L, Labrincha JA, Ferreira VM, Hotza D, Repette WL. Effect of nano-silica on rheology and fresh properties of cement pastes and mortars. Constr Build Mater 2009;23:2487-91.

[8] Lin KL, Chang WC, Lin DF, Luo HL, Tsai MC. Effects of nano- $\mathrm{SiO}_{2}$ and different ash particle sizes on sludge ash-cement mortar. J Environ Manage 2008;88:708-14.

[9] Bjornstrom J, Martinelli A, Matic A, Borjesson L, Panas I. Accelerating effects of colloidal nano-silica for beneficial calcium-silicate-hydrate formation in cement. Chem Phys Lett 2004:392:242-8.

[10] Senff L, Hotza D, Repette WL, Ferreira VM, Labrincha JA. Mortars with nano$\mathrm{SiO}_{2}$ and micro- $\mathrm{SiO}_{2}$ investigated by experimental design. Constr Build Mater 2010;24(8):1432-7.

[11] Ji T. Preliminary study on the water permeability and microstructure of concrete incorporating nano-SiO 2 . Cem Concr Res 2005;35:1943-7.

[12] Li G. Properties of high-volume fly ash concrete incorporating nano- $\mathrm{SiO}_{2}$. Cem Concr Res 2004:34:1043-9.

[13] Gaitero JJ, Campillo I, Guerrero A. Reduction of the calcium leaching rate of cement paste by addition of silica nanoparticles. Cem Concr Res 2008;38:1112-8.

[14] Green BH. Development of a high-density cementitious rock-matching grout using nano-particles. In: Proceedings of ACI session on nanotechnology of concrete: recent developments and future perspectives, November 7, Denver, USA; 2006. p. 119-30.

[15] Sobolev K, Ferrara M. How nanotechnology can change the concrete world Part 2. Am Ceram Bull 2005;84(11):16-20.

[16] Sobolev K, Ferrara M. How nanotechnology can change the concrete world Part 1. Am Ceram Bull 2005;84(10):14-7.

[17] Sobolev K, Flores I, Hermosillo R. Nanomaterials and nanotechnology for highperformance cement composites. In: Proceedings of $\mathrm{ACI}$ session on nanotechnology of concrete: recent developments and future perspectives, November 7, Denver, USA; 2006. p. 91-118.

[18] Belkowitz JS, Armentrout D. An investigation of nano-silica in the cement hydration process. In: Proceeding 2010 concrete sustainability conference, national ready mixed concrete association, USA; 2010. p. 1-15.

[19] Quercia G, Brouwers HJH. Application of nano-silica (nS) in concrete mixtures. In: Gregor Fisher, Mette Geiker, Ole Hededal, Lisbeth Ottosen, Henrik Stang, editors. 8th fib International Ph.D. symposium in civil engineering, June 20-23, Lyngby, Denmark; 2010. p. 431-6.

[20] Rols S, Ambroise J, Péra J. Effects of different viscosity agents on the properties of self-leveling concrete. Cem Concr Res 1999;29:261-6.

[21] Okamura H, Ozawa K. Mix-design for self-compacting concrete. Concr Libr, Jpn Soc Civ Eng - JSCE 1995;25:107-20.

[22] Audenaert K, Boel V, De Schutter G. Chloride migration in self compacting concrete. In: Proceeding fifth international conference on concrete under severe conditions: environment and loading (CONSEC'07), June 4-6, Tours, France; 2007. p. 191-298.

[23] Byung WJ, Chang HK, Jae HL. Investigations on the development of powder concrete with nano-SiO 2 particles. KSCE J Civ Eng 2007;11(1):37-42.

[24] Collepardi M, Ogoumah JJ, Skarp U, Troli R. Influence of amorphous colloidal silica on the properties of self-compacting concretes. In: Proceedings of the international conference challenges in concrete construction - innovations and developments in concrete materials and construction, 9-11 September, Dundee, Scotland, UK; 2002. p. 473-83.

[25] Sari M, Prat E, Labastire JF. High strength self-compacting concrete original solutions associating organic and inorganic admixtures. Cem Concr Res 1999;29:813-8.

[26] Sadrmomtazi A, Barzegar A. Assessment of the effect of nano- $\mathrm{SiO}_{2}$ on physical and mechanical properties of self-compacting concrete containing rice husk ash. In: Proceedings second international conference on sustainable construction materials and technologies, June 28-30, Universita Politecnica delle Marche, Ancona, Italy; 2010. p. 1-9.

[27] Maghsoudi AA, Arabpour-Dahooei F. Effect of nanoscale materials in engineering properties of performance self compacting concrete. In: Proceeding of the 7th international congress on civil engineering, Iran; 2007. p. 1-11.

[28] Khanzadi M, Tadayon M, Sepehri H, Sepehri M. Influence of nano-silica particles on mechanical properties and permeability of concrete. In: Proceedings second international conference on sustainable construction materials and technologies, June 28-30, Universita Ploitecnica delle Marche, Ancona, Italy; 2010. p. 1-7.

[29] Raiess-Ghasemi AM, Parhizkar T, Ramezanianpour AA. Influence of colloidal nano- $\mathrm{SiO}_{2}$ addition as silica fume replacement material in properties of concrete. In: Proceedings second international conference on sustainable construction materials and technologies, June 28-30, Universita Ploitecnica delle Marche, Ancona, Italy; 2010. p. 1-8.

[30] Baomin W, Lijiu W, Lai FC. Freezing resistance of HPC with nano-SiO ${ }_{2}$.J Wuhan Univ Technol, Mater Sci ed 2008;23(1):85-8.

[31] Wei X, Zhang P. Sensitivity analysis for durability of high performance concrete containing nanoparticles based on grey relational grade. Mod Appl Sci 2011;5(4):68-73.
[32] ENCI BV. Betonpocket 2010. The Netherlands: Heidelberg Cement Group‘sHertogenbosch; 2009. p. 1-288 [in Dutch].

[33] Brunauer S, Emmet PH, Teller E. Adsorption of gases in multimolecular layers. Am Chem Soc 1938;62:309-19.

[34] DIN ISO 9277. Determination of the specific surface area of solids by gas adsorption using the BET method. German Institute of Normalization-DIN; 2005. p. 1-19.

[35] Hunger M. An integral design concept for ecological self-compacting concrete. Ph.D. thesis. Eindhoven University of Technology, The Netherlands; 2010.

[36] Hüsken G, Brouwers HJH. A new mix design concept for earth-moist concrete: a theoretical and experimental study. Cem Concr Res 2008;38:1246-59.

[37] Dutch Normalization-Institute. Nederlandse invulling van NEN-EN 206-1: Beton Deel 1: specificatie, eigenschappen, vervaardiging en conformiteit Nederlands Normalisatie Instituut, Delft, The Netherlands; 2008. p. 1-72.

[38] BMC Certificatie BRL 1801: Nationale Beoordelingsrichtlijn Betonmortel. BMC Certificatie, Gouda, The Netherlands; 2006 [in Dutch].

[39] Specification and guidelines for Self Compacting Concrete-SCC. In: Report European Federation of Producers and Contractors of Specialist Products for Structures EFNARC, Surrey, UK; 2005.

[40] BS-EN 12390-2. Testing hardened concrete - Part 2: making and curing specimens for strength tests. British Standards Institution-BSI and CEN European Committee for Standardization; 2000. p. 1-10.

[41] BS-EN 12390-3. Testing hardened concrete - compressive strength of test specimens. British Standards Institution-BSI and CEN European Committee for Standardization; 2009. p. 1-22.

[42] BS-EN 12390-6. Testing hardened concrete - tensile splitting strength of test specimens. British Standards Institution-BSI and CEN European Committee for Standardization; 2000. p. 1-14.

[43] Safiuddin Md, Hearn N. Comparison of ASTM saturation techniques for measuring the permeable porosity of concrete. Cem Concr Res 2005;35:1008-13.

44] ASTM C1202. Standard test method for electrical indication of concrete's ability to resist chloride ion penetration. In: Annual Book of ASTM Standards, vol. 04.02. Philadelphia: American Society for Testing and Materials; 2005. p. $1-6$.

[45] BS-EN 12390-8. Testing hardened concrete - depth of penetration of water under pressure. British Standards Institution-BSI and CEN European Committee for Standardization; 2009. p. 1-10.

[46] Nordtest method NT Build 492. Concrete, mortar and cement-based repai materials: chloride migration coefficient from non-steady-state migration experiments. Finland 1999:1-8.

47] Spiesz P, Ballari MM, Brouwers HJH. RCM: a new model accounting for the non-linear chloride binding isotherm and the non-equilibrium conditions between the free- and bound-chloride concentrations. Constr Build Mater 2012;27:293-304.

48] Polder RB. Test methods for onsite measurement of resistivity of concrete RILEM TC-154 technical recommendation. Constr Build Mater 2001;15:125-1301.

[49] Bentz DP, Jensen OM, Coats AM, Glasser FP. Influence of silica fume on diffusivity in cement-based materials I. Experimental and computer modeling studies on cement pastes. Cem Concr Res 2000;30:953-62.

[50] Tang L."Chloride transport in concrete - measurement and prediction. PhD thesis. Chalmers University of Technology, Gothenburg, Sweden; 1996.

[51] Nordtest method NT Build 443. Concrete, hardened: accelerated chloride penetration. Finland 1995:1-5.

[52] Yuan Q. Fundamental studies on test methods for transport of chloride ions in cementitious materials. PhD thesis. Universiteit Gent, Belgium; 2009. p. 1340.

[53] NEN-EN 12390-9. Testing hardened concrete - freeze-thaw resistance scaling. CEN European Committee for Standardization and Dutch Normalization-Institute, Delft, The Netherlands; 2006. p. 1-29 [in English].

[54] Plank J, Schroefl Ch, Gruber M, Lesti M, Sieber R. Effectiveness of polycarboxylate superplasticizer in ultra-high strength concrete: the importance of PCE compatibility with silica fumel. J Adv Concr Technol 2009;7(1):12-5.

[55] Spiratos N, Page M, Mailvaganam NP, Malhotra VM, Jolicoeur C. Superplasticizer for concrete. Fundamentals, technology, and practice. Otawa, Canada: Supplementary Cementing Materials for Sustainable Development Inc.; 2003. p. 1-321.

[56] Kordts S, Breit W. Combined test method for assessing the workability of SCCflow cone. In: Concrete technology reports; 2004-2006. p. 7-15.

[57] Felekoglu B. Utilization of high volumes of limestone quarry wastes in concrete industry (self-compacting concrete case). Resour, Conserv Recycl 2007:51:770-91.

[58] Piechowka-Mielnik M, Giergiczny Z. Properties of Portland-composite cement with limestone. In: Proceeding of the XIII international conference on cement chemistry, July 4-8, Madrid; 2011. p. 1-7.

[59] ECETOC JACC REPORT No. 51. Synthetic amorphous silica (CAS No. 7631-86-9). European Centre for Ecotoxicology and Toxicology of Chemicals, Brussels, September; 2006. p. 1-231.

[60] Iler RK. The colloid chemistry of silica and silicate. New York: Edit. Ithaca; 1955. p. 1-250.

[61] Madani H, Bagheri A, Parhizkar T. The pozzolanic reactivity of monodispersed nanosilica hydrosols and their influence on the hydration characteristics of Portland cement. Cem Concr Res 2012;42:1563-70. 
[62] Kong D, Su Y, Du X, Yang Y, Wei S, Shah SP. Influence of nano-silica agglomeration on fresh properties of cement pastes. Constr Build Mater 2013;37:557-62.

[63] Berra M, Carassiti F, Mangialardi T, Paolini AE, Sebastiani M. Effecs of nanosilica addtion on workability and compressive strength of Portland cement pastes. Constr Build Mater 2012;35:666-75.

[64] Kong D, Du X, Wei S, Zhang H, Yang Y, Shah SP. Influence of nano-silica agglomeration on microstructure and properties of the hardened cementbased materials. Constr Build Mater 2012;37:707-15.

[65] Zhang M, Ilsam J, Peethamparan S. Use of nano-silica to increase early strength and reduce setting time of concretes with high volumes of slag. Cem Concr Compos 2012;34:650-62.

[66] Jalal M, Mansouri E, Sharifipour M, Pouladkhan AR. Mechanical, rheological, durability and microstructural properties of high performance selfcompacting concrete containing $\mathrm{SiO}_{2}$ micro and nanoparticles. Mater Des 2012:34:389-400.

[67] Mondal P, Shah SP, Marks LD, Gaitero JJ. Comparative study of the effects of microsilica and nanosilica in concrete. Transportation Research Record: Journal of the Transportation Research Board, No. 2141. Washington, DC: Transportation Research Board of the National Academies; 2010. p. 6-9.

[68] Neville AM. Properties of concrete. 4th ed. Harlow, UK: Prentice Hall/Pearson; 2002. p. 537-76.

[69] Garboczi EJ. Permeability, diffusivity, and microstructural parameters: a critical review. Cem Concr Res 1990;20:591-601.

[70] Yogendran V, Langan BW. Utilization of silica fume in high strength concrete. In: Proceedings of utilization of high strength concrete Stavanger. Norway: Tapir Publisher Trondheim; 1987.

[71] Mindess S, Young JF, Darwin D. Concrete. 2nd ed. Upper Saddle River, New Jersey: Prentice Hall; 2003.

[72] Lotenbach B, Scrivener K, Hooton RD. Supplementary cementitious materials. Cem Concr Res 2001;41:1244-56.

[73] Ye G. Experimental study and numerical simulation of the development of the microstructure and permeability of cementitious materials. PhD thesis. Delft University of Technology, Delft; December 18 2003. p. 1-189.

[74] Shih JY, Chang TP, Hsiao TCh. Effect of nano-silica on characterization of Portland cement composite. Mater Sci Eng A 2006;424:266-74.
[75] Desmet D, Hernandez J, Willain L, Vantomme J. Porosity determination of selfcompacting concrete using forced saturation. In: Proceeding of the XII international conference on cement chemistry, July 4-8, Madrid; 2011. p. 1-7.

[76] Andrade C, D'Andrea R, Lopez JC, Cienfuegos-Jovellano A, Alvarez JM, Millan JM. Use of electrical resistivity as complementary tool for controlling the concrete production. In: Proceeding of the XIII international conference on cement chemistry, July 4-8, Madrid; 2011. p. 1-7.

[77] Andrade C, Rio O, Castillo A, Castellote M, D'Andrea R. A NDT performance method based on electrical resistivity for the specification of concrete durability. In: ECCOMAS thematic conference on computational methods in tunnelling, August 27-29, Vienna, Austria; 2007. p. 1-9.

[78] Bagheri AR, Zanganeh $\mathrm{H}$, Moalemi MM. Mechanical and durability properties of ternary concretes containing silica fume and low reactivity blast furnace slag. Cem Concr Compos 2012;34:663-70.

[79] DuraCrete. Probabilistic performance based durability design of concrete structures. In: DuraCrete final technical report. Document BE95-1347/R17; 2000.

[80] CUR Durability Guideline. Duurzaamheid van constructief beton met betrekking tot chloride-geïnitieerde wapeningscorrosie. CUR Bouw en Infra. Gouda, The Netherlands; 2009. p. 1-65 [in Dutch].

[81] Romero HL, Casati MJ, Galvez JC, Molero M, Segura I. Study of the damage evolution of concrete under freeze-thaw cycles using traditional and nontraditional techniques. In: Proceeding of the XIII international conference on cement chemistry, July 4-8, Madrid; 2011. p. 1-7.

[82] Stark J, Wicht B. Dauerhaftigkeit von Beton: Der Baustoff als Werkstoff, Birkhäuser, Basel, Switzerland; 2001 [in German].

[83] Nocun-Wczelik W, Loj G. Effect of finely dispersed limestone additives of different origin on cement hydration kinetics and cement hardening. In: Proceeding of the XIII international conference on cement chemistry, July 4-8, Madrid; 2011. p. 1-7.

[84] Lothenbach B, Le Saout G, Gallucci E, Scrivener K. Influence of limestone on the hydration of Portland cements. Cem Concr Res 2008;38:848-60.

[85] Bonavetti VL, Rahhal VF, Irassar EF. Studies on the carboaluminate formation in limestone filler-blended cements. Cem Concr Res 2001;31:853-9.

[86] Taylor HFW. Cement chemistry. London: Academic Press; 1990. 